\title{
Investigation of Electrical Properties of P3HT:PCBM Organic Solar Cells
}

\author{
A Thesis \\ Presented to \\ The Faculty of the School of Engineering and Applied Science \\ University of Virginia \\ In Partial Fulfillment \\ of the Requirements for the Degree \\ Doctor of Philosophy in Electrical Engineering
}

\author{
by \\ Yang Shen
}

December, 2013 


\section{Approval Sheet}

The thesis is submitted in partial fulfillment of the requirements for the degree of Doctor of Philosophy in Electrical Engineering

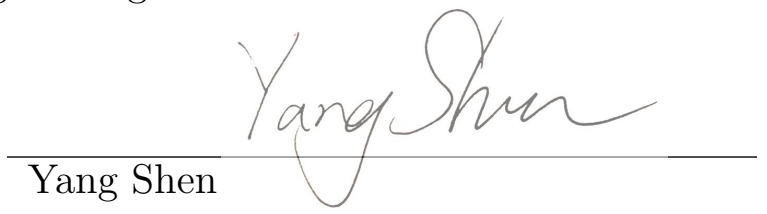

This proposal has been read and approved by the Examining Committee:

\begin{tabular}{l}
\hline Mool C. Gupta, Ph.D., Dissertation Advisor \\
\hline Joe C. Campbell, Ph.D., Committee Chairman \\
\hline John C. Bean, Ph.D., Committee Member \\
\hline Lin Pu, Ph.D., Committee Member \\
\hline Lloyd R. Harriott, Ph.D., Committee Member
\end{tabular}

Accepted for the School of Engineering and Applied Science:

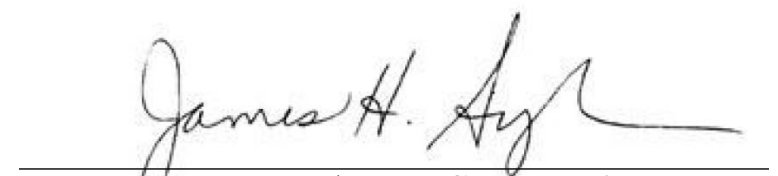

Dean James H. Aylor, School of Engineering and Applied Science

December, 2013 


\section{Abstract}

The electrical properties of organic solar cells (OSC) have been investigated to understand the charge loss mechanisms impacting the over all efficiency. The power conversion efficiency of a solar cell is dependent upon the short-circuit current density $\left(J_{S C}\right)$, open circuit voltage $\left(V_{O C}\right)$ and the fill factor $(\mathrm{FF})$. This thesis is mainly about the investigation of these properties in two aspects: the current conducting mechanism is studied via electrical resistance measurements of the OSC devices and the origin of $V_{O C}$ is investigated through the fundamental studies using ultraviolet photoelectron spectroscopy (UPS).

In the current conducting mechanism study, the series resistance of poly (3hexylthiophene-2,5-diyl) (P3HT) and [6,6]-phenyl C61-butyric acid methyl ester (PCBM) bulk heterojunction (BHJ) organic solar cells (OSC) has been investigated. The bulk resistance of the active layer and the specific contact resistance between the active layer and the electrode are extracted from the measured series resistance using the vertical transmission line model (TLM) method. Results have shown that for an annealed P3HT:PCBM device which has an active layer thickness of $85 \mathrm{~nm}$ (optimum thickness for high efficiency), $17 \%$ of the total series resistance is attributed to contact resistance and bulk resistance contributed the rest 83\%. Thermal annealing helps to reduce the contact resistance by a factor of 2 and the bulk resistance by a factor of 8. The resistances of pure PCBM devices increase linearly with thickness, while the increasing trend of the pure P3HT devices can be described as two different increasing regions, mainly due to the recombination effect.

The origin of $V_{O C}$ is investigated through UPS study. $V_{O C}$ of P3HT and PCBM

organic solar cell devices is measured at temperatures ranging from $15^{\circ} \mathrm{C}$ to $145^{\circ} \mathrm{C}$. 
The temperature dependence of the vacuum level shift and of the highest occupied molecular orbital (HOMO) energy level of P3HT and PCBM are measured by UPS in the same temperature range. The temperature dependence of the absorption edge is also studied in the same temperature range to obtain the temperature variation of the optical band gap energy $\left(E_{g}\right)$. The measured $V_{O C}$ of the devices shows a clear decreasing trend with the increased operating temperatures and the total decrease is found to be about $0.1 \mathrm{~V}$ at the temperatures ranging from $15{ }^{\circ} \mathrm{C}$ to $145^{\circ} \mathrm{C}$ However, by utilizing the measured values of the HOMO for the P3HT (donor) and LUMO for the PCBM (acceptor), the calculated values of $V_{O C}$ and its temperature dependence shows an increasing trend with temperatures. The calculated values of $V_{O C}$ do not agree with the measured $V_{O C}$ values. This is a clear indication that the expression (HOMO - LUMO) - exciton binding energy does not hold, and that other factors are impacting the value of $V_{O C}$.

The thermal conductivities of P3HT, PCBM and P3HT:PCBM blend are measured by time domain thermoreflectance. Thermal conductivities vary from $0.031 \pm$ $0.005 \mathrm{~W} \mathrm{~m}^{-1} \mathrm{~K}^{-1}$ for pure PCBM to $0.227 \pm 0.014 \mathrm{~W} \mathrm{~m}^{-1} \mathrm{~K}^{-1}$ for pure P3HT near room temperature. PCBM shows much lower thermal conductivity than P3HT. Thermal conductivities of blend films follow a rule of mixtures and no percolation threshold is found. Thermal annealing of blend films has a variable effect on thermal conductivity. 


\section{Acknowledgments}

I would never have been able to finish my dissertation without the guidance of my advising committee, help from my friends and support from my family.

I would like to express my deepest gratitude to my advisor, Dr. Mool C. Gupta, for his kind guidance, caring, patience and providing me with a fantastic atmosphere for doing research.

I would also like to thank Dr. Louis Scudiero, Dr. Joe C. Campbell and Dr. Patrick Hopkins for research collaboration for the past several years and helping me for the dissertation.

I would like to sincerely thank my group members and colleagues for their support. Special thanks to Dr. Jiguang Li, who as my office buddy and old friend, is always willing to help and give his best suggestions. Special thanks to Keye Sun, Christian Rothenbach, Kejia Li and all my friends for the help. It would have been a lonely Ph.D term without them.

Many thanks to the great staff of the Department of Electrical and Computer Engineering for their kind help throughout many years. Special thanks to the clean room facility management staff for all the hard work that keep equipments running. My research would not have been possible without them.

Moreover, thanks to Dr. Anping Liu and Dr. Barada 'BK' Nayak for their kind support during my internships and helping me broaden my research vision.

Thanks to my family. Tens of thousands of miles away, they are always able to surround me with their love and support. Lastly, I would like to thank my parents. Dear Mom and Dad, thank you for everything! Your son, Yang. 


\section{Contents}

List of Figures viii

$\begin{array}{lll}1 & \text { Introduction } & 1\end{array}$

1.1 Solar Cells . . . . . . . . . . . . . . . . . . . . . . . . . . . . . . 1

$1.2 \quad$ Organic Solar Cells . . . . . . . . . . . . . . . . . . . . . . . . . 6

1.2 .1 Materials Properties . . . . . . . . . . . . . . 7

1.2 .2 Device Structure $\quad \ldots \ldots \ldots$

1.2 .3 Device Fabrication . . . . . . . . . . . . . . . . . . . . . 14

1.2 .4 Operation Mechanism . . . . . . . . . . . . . . . . . . 16

1.2 .5 Device Characterization . . . . . . . . . . . . . . 18

1.3 Thesis Outline. . . . . . . . . . . . . . . . . . . . . . 20

2 Charge Transport Mechanism Study 23

2.1 Statement of the Problem . . . . . . . . . . . . . . . . . . . 23

2.2 Experiments and Data Analysis . . . . . . . . . . . . . . . . . . 25

2.3 Resistance of P3HT:PCBM solar cells . . . . . . . . . . . . . . 30

2.4 Resistance of Pure P3HT and PCBM . . . . . . . . . . . . . . . . 34

2.5 Conclusions and Future work $\ldots \ldots \ldots \ldots \ldots$

3 Origin of $V_{O C} \quad 42$

3.1 Statement of the Problem . . . . . . . . . . . . . . . . . . 42

3.2 Experiments . . . . . . . . . . . . . . . . . . . . . . . . . . . . 44

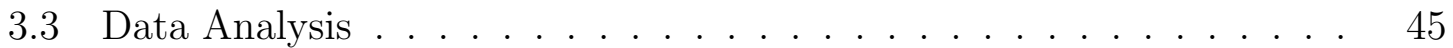

3.3.1 Capacitance Measurements for Exciton Binding Energy Calcu-

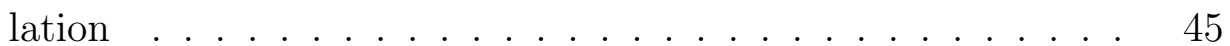

$3.3 .2 \quad$ HOMO LUMO levels and Exciton Binding Energy . . . . . . . 47

3.4 Discussion $\ldots \ldots \ldots \ldots \ldots \ldots \ldots$

3.5 Conclusion and Future work $\ldots \ldots \ldots \ldots \ldots$

\begin{tabular}{|lll}
4 & Thermal Conductivity Study of Organic Solar Cell Materials & 56
\end{tabular}

4.1 Background $\ldots \ldots \ldots \ldots \ldots \ldots$

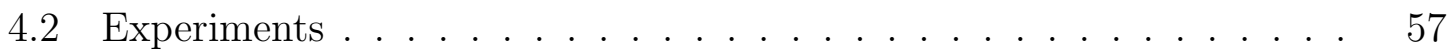


4.3 Results and Discussion . . . . . . . . . . . . . . . . . . . . . . . 58

4.4 Conclusions . . . . . . . . . . . . . . . . . . . . . . . . . 63

$\begin{array}{lll}5 & \text { Conclusions } & 64\end{array}$

$\begin{array}{lll}6 & \text { Bibliography } & 66\end{array}$

\begin{tabular}{ll}
\hline Appendices & 78
\end{tabular}

\begin{tabular}{ll}
\hline A Journal Publications & 79
\end{tabular}

\begin{tabular}{|lr}
\hline B Conference Presentations & 81
\end{tabular} 


\section{List of Figures}

1.1 Primary Energy Production by Source (2012)[6] . . . . . . . . . . . . 3

1.2 Renewable Energy Production by Source (2012)[6] . . . . . . . . . . . 4

$1.3 \quad$ Photovoltaic market share $(2010)[8] \ldots \ldots \ldots$. . . . . . . . . . 5

1.4 Structure of M-PPV, $\mathrm{C}_{60}, \mathrm{P} 3 \mathrm{HT}, \mathrm{PCBM}, \mathrm{PCPDTBT}, \mathrm{PC}_{71} \mathrm{BM}[16-21] \quad 8$

1.5 Solar emission spectrum (AM 1.5) [1,2] and absorption spectrum of an $80 \mathrm{~nm}$ thick P3HT/PCBM blend film . . . . . . . . . . . . . . 9

1.6 The structure of organic solar cells: bilayer (left),bulk heterojunction

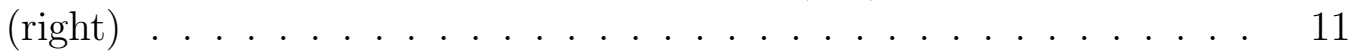

1.7 Schematic representations of the model used to fit the ellipsometry data, showing typical PCBM distributions (a) before and (b) after thermal annealing [22]] . . . . . . . . . . . . . . . . . . . . 12

1.8 Electrical field intensity distribution in P3HT/PCBM solar cell device with (a) and without (b) $\mathrm{TiO}_{x}$ spacer . . . . . . . . . . . . . 13

1.9 P3HT:PCBM solar cells structure . . . . . . . . . . . . . . . . . 14

1.10 P3HT:PCBM solar cells fabricating procedures . . . . . . . . . . . 15

1.11 A general absorption and charge transport mechanism in an P3HT:PCBM OSC device . . . . . . . . . . . . . . . . . . 16

1.12 Typical J-V curves for a P3HT/PCBM OSC device under AM1.5 illumination with key performance parameters noted . . . . . . . . . . . 19

2.1 Device structure of P3HT:PCBM solar cell . . . . . . . . . . . . . . 25

2.2 Efficiency comparison of devices with and without epoxy resin coating, both devices are left in air with room light on for one week . . . . . . 27

2.3 Equivalent circuit model of solar cells . . . . . . . . . . . . . . 28

2.4 The I dV/dI vs. I curve for an organic solar cell . . . . . . . . . . . . 29

\begin{tabular}{ll|}
\hline 2.5 & $R_{S}$ of P3HT:PCBM organic solar cells with different active layer thick- \\
\hline
\end{tabular} were conducted in dark. . . . . . . . . . . . . . . . . . . . 30

2.6 Linear fitting to $R_{S}$ versus active layer thickness. . . . . . . . . . . . 31

$2.7 \quad R_{S}$ of P3HT device(ITO/P3HT/Al) with different P3HT layer thicknesses. . . . . . . . . . . . . . . . . . . . 34 
$2.8 R_{S}$ of PCBM device (ITO/PEDOT/PCBM/Al) with different PCBM

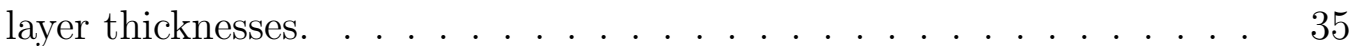

2.9 Curve fitting for P3HT devices (ITO/P3HT/Al) with different active layer thicknesses. . . . . . . . . . . . . . . . 36

2.10 Reisitivity of P3HT device (ITO/P3HT/Al) with different P3HT layer thicknesses. . . . . . . . . . . . . . 37

3.1 A typical C-V characteristic curve of P3HT/PCBM BHJ solar cell . . 45

3.2 Equivalent circuit model of a schottky junction $\ldots \ldots$. . . . . . 46

3.3 Ionization energy of P3HT $\left(I_{P D}\right)$ and electron affinity of $\operatorname{PCBM}\left(E_{A A}\right)$ as a function of temperature ranging from $25^{\circ} \mathrm{C}$ to $145{ }^{\circ} \mathrm{C}$. . . . . . . 47

3.4 (a) The capacitance of $\mathrm{P} 3 \mathrm{HT}$ in the temperature ranging from $25^{\circ} \mathrm{C}$ to $145^{\circ} \mathrm{C}$. (b)The permittivity of P3HT from $25^{\circ} \mathrm{C}$ to $145^{\circ} \mathrm{C}$. (c)Calculated exciton binding energy with the measured permittivity of P3HT. . . . 49

3.5 Comparison of calculated and experimental values of $V_{O C}$ as a function

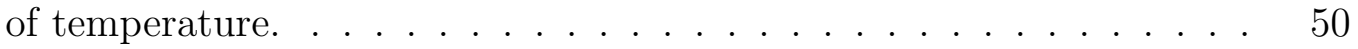

3.6 Comparison of calculated $V_{O C}$ with experimental measured values of $V_{O C}$ as a function of temperature. . . . . . . . . . . 52

4.1 Thermal conductivities of the PEDOT:PSS, P3HT, PCBM, and P3HT:PCBMI films, along with previously published thermal conductivities of amorphous carbon (dashed line), thin film PCBM (open squares), and P3HT (open circle).[81]] . . . . . . . . . . . . . . . . 60

4.2 Thermal conductivities of the P3HT:PCBM blend films as a function of weight percent P3HT.[81] . . . . . . . . . . . . . . . 61

4.3 Electron diffraction patterns of (a) unannealed and (b) annealed PCB$\mathrm{M}$ films. Note the rings in diffraction pattern from the annealed sample are more distinct than they are in the unannealed sample, indicating an increase in crystallinity.[81]] . . . . . . . . . . . . . . . . . . 62

4.4 Thermal conductivities of P3HT (filled circles), CuPc (hollow squares) and PCBM (hollow diamonds) films as a function of film thickness.[81] 63 


\section{Chapter 1}

\section{Introduction}

\section{$1.1 \quad$ Solar Cells}

The sun is a vast source of energy. The intensity of the solar spectral irradiance on the surface of the earth is $1000 \mathrm{~W} / \mathrm{m}^{2}$ (Air Mass 1.5) [1,2]. Solar cells were invented to harvest the energy from sunlight. A solar cell is a solid state electrical device which converts light directly into electricity by the photovoltaic effect. The conversion of light into electricity is accomplished by absorbing photons with enough energy to ionize atoms, and thereby creating free, negatively charged electrons and positively charged ions. The energy of the photons is therefore transferred into the electrons and holes. These charge carriers can be collected by separate electrodes. As a result, photovoltage formed between electrodes and electricity is generated. The first modern solar cell was a silicon based single p-n junction device developed in 1954 at Bell Laboratories [3]. The developers, Gerald Pearson, Daryl Chapin and Calvin Fuller, reported a power conversion efficiency of $6 \%$,4,5]. Solar cells were quickly added to the Vanguard I satellite as a sustainable power source. It proved to be a huge success in replacing the old battery power source. The booming semiconductor 
industry helped to bring down the cost of silicon based solar cells from $\$ 100$ per watt in 1971 to $\$ 1.09$ per watt in October 2011. This made it possible for solar cells to be a competitive renewable energy source from only a power source of satellites [5].

There are many advantages of utilizing solar energy as a renewable energy source. Solar cells can be used almost anywhere. They are cost effective solutions to energy problems in places where there is no grid electricity. Solar cells are also clean, zero noise and non-polluting. They produce no waste, they have no moving parts, and they require little maintenance in a relatively long lifetime. Solar cells are also easy to integrate. They can be placed on rooftops and roadside; they can be used as building windows, walls or roof. Compared with other renewable sources, such as wind and water power, solar power does not rely on turbines which are noisy, expensive and vulnerable to breakdowns. 


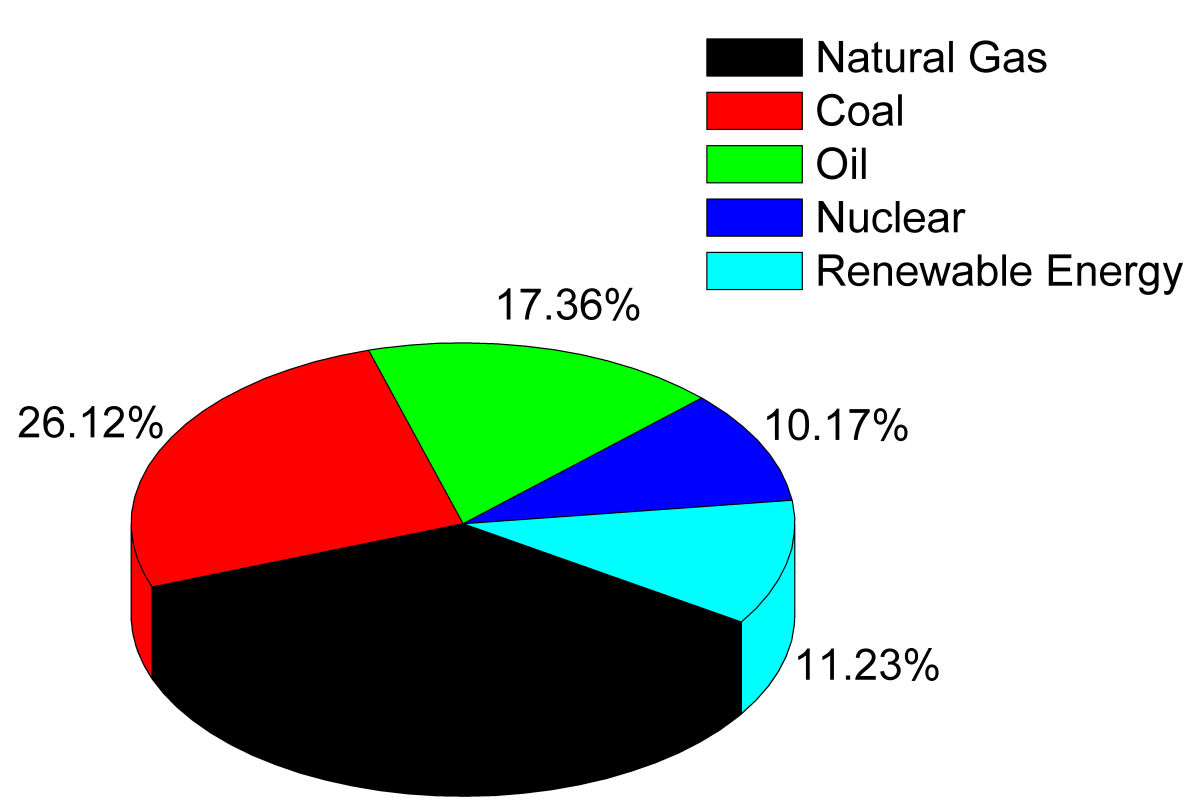

$35.12 \%$

Figure 1.1: Primary Energy Production by Source (2012)[6]

Figure 1.1 shows the percentage of all energy production in United States by source. By the year 2012, $10 \%$ of the total energy produced in the United States is from renewable energy sources $[6]$. Figure 1.2 shows the percentage of all renewable energy production by source. Solar energy provides $2 \%$ of total energy produced from renewable energy sources, compared with $50 \%$ from biomass, $30 \%$ from hydroelectric power and $15 \%$ from wind $[6]$. One may ask, with all the advantages, why solar energy makes up only $2 \%$ of the total renewable energy production? 


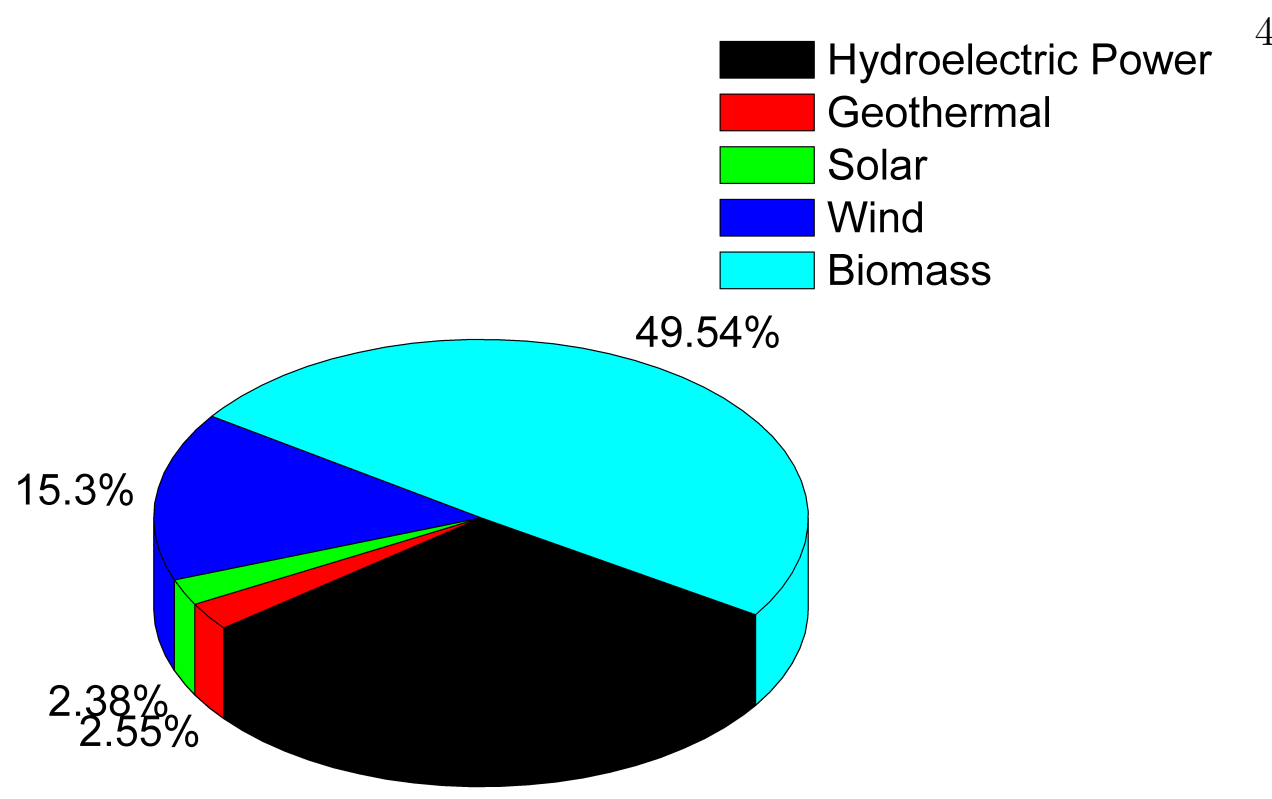

$30.21 \%$

Figure 1.2: Renewable Energy Production by Source (2012)[6]

Despite all the advantages, there are several disadvantages which make solar energy less competitive in the renewable energy market. The main one is high cost. The price of electricity generated from solar panels is relatively higher than the price of electricity generated from most of the other sources. Single junction silicon solar cell has a theoretical efficiency limit of $30 \%$, known as as the Shockley-Queisser limit [7. The silicon itself is not cheap, and as a result, the price of solar panels are greatly dependent on raw silicon price. Solar cells can only generate power during daytime under suitable weather, which makes the output unstable. Other complex issues such as grid compatibility and electricity storage need to be addressed to make solar energy more competitive. Tremendous efforts have been made on all those issues, which helps solar energy to grow rapidly in recent years. However, to further increase the competitiveness of solar power, massive investments are still needed to 
further increase cell efficiency and lower panel cost.

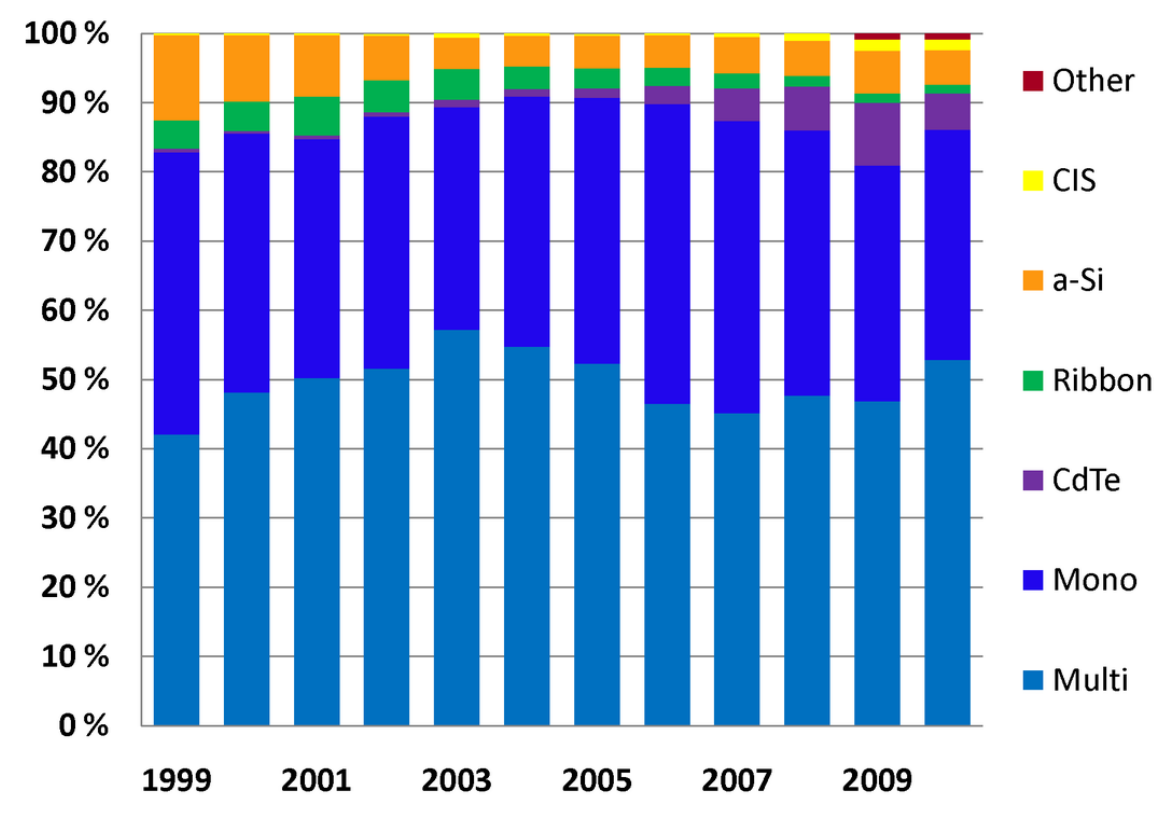

Figure 1.3: Photovoltaic market share (2010)[8]

Figure 1.3 is a chart that shows the market share of different photovoltaic technologies from 1999 to 2011 [8]. Light blue and dark blue bars represent multi and mono crystalline silicon respectively. Together they represented $87 \%$ of the market share in 2010. The green bars represent Ribbon solar cell, which is actually multi-crystalline silicon solar but with different manufacturing process. By avoiding the need for sawing of silicon blocks in the manufacturing process, ribbon solar cells benefit from less expensive manufacturing techniques but do not have the same efficiency performance as wafer cut solar cells. Together conventional silicon solar cells dominate almost 90 $\%$ of the solar cell market. 
Thin film solar cells constitute the rest $10 \%$. Thin film solar cells are designed to reduce the cost of solar cells by using less silicon or substituting silicon with other light-absorbing materials. They succeed in reducing some of the cost, but other problems arise at the same time. They suffer from low efficiency and complex and expensive fabrication processes. Amorphous silicon (a-Si) solar cells are one of the three mainstream thin film solar cells. The approach to reduce cost is to use much less amount of silicon. A-Si cells use approximately $1 \%$ of the silicon needed by typical crystalline-Si cells. This makes the cells considerably cheaper. However, the efficiency is much lower too. Cadmium telluride (CdTe) photovoltaics is a photovoltaic (PV) technology that is based on the use of CdTe thin films. CdTe PV is the only thin film photovoltaic technology that is cheaper than crystalline silicon PV. Copper indium gallium selenide ( $C u I n_{1-x} G a_{x} S e_{2}$ or CIGS) is one of the other mainstream thin film solar cells. CIGS is a direct bandgap semiconductor. The CIGS absorber is deposited on a glass or plastic backing, along with electrodes on the front and back to collect current. Because the material has a high absorption coefficient, a much thinner film is required compared with other semiconductor materials.

\section{$1.2 \quad$ Organic Solar Cells}

Organic solar cell (OSC) is a relatively new concept, yet hold the promise for further price reduction due to its advantage of solution processable technique. Compared with inorganic solar cells where the active layers are generally semiconductors, such as silicon, the compounds used to make organic solar cells are small molecules and polymers, which can be dissolved in solutions and then be printed as thin films (100 $\mathrm{nm}$ ) on substrates [9]. With fairly high absorption coefficient, $100 \mathrm{~nm}$ thin organic active layer can absorb a respective amount of sunlight which takes much thicker 
silicon to absorb. Thus it is possible for OSC to further bring down the cost from raw material in the solar panel production. On the other hand, the category of the organic materials is constantly expanding as previous ones are modified to make new compounds with better properties. The efficiency record of lab produced OSC jumped a lot recent years. However, OSC is not very successful when entering the real market, mainly due to its low efficiency compared with most of other solar cells. Konarka Technologies, Inc., a famous organic solar cell company, filed for bankruptcy protection in May 2012. While many people suggest that an efficiency of at least $15 \%$ is necessary for organic solar cells to establish a viable market [10], the highest efficiency achieved in organic devices to date is $10.7 \%$ reported by Mitsubishi Chemical in April 2012, but efficiency continue to improve. The efficiency record are from Solar cell efficiency tables (version 42) [11.

\subsubsection{Materials Properties}

The core part of an OSC is the active layer consists of organic molecules and polymeric semiconductors. Those molecules possess $\pi$-atomic orbitals and the conjugation of these $\pi$ obitals results in HOMO (highest occupied molecules orbital) and LUMO (lowest unoccupied molecules orbital) levels, similar to valence band and conduction band in semiconductors [12]. The optical prosperities such as optical band gap are determined by the HOMO and LUMO levels. As a matter of fact, the unique optical prosperities of these organic materials make them suitable for photovoltaic applications. Their light absorption properties can be summarized in two words: intense and broad. They have a high extinction coefficient $\left(>10^{5} \mathrm{~cm}^{-1}\right)$ because of the large wave-function between the ground state and the lowest excited state, which makes it possible for sufficient light absorption with films thinner than $100 \mathrm{~nm}$. They can be 
fabricated to have a small optical band gap (as small as $1 \mathrm{eV}$ ), which allows them to absorb most of the solar spectrum $13 \sqrt{15}]$.

The organic molecular structure and their interactions determine their electrical properties. These materials usually exhibit low charge carrier mobilities. Unlike crystalline material with highly ordered lattice, organic polymers and small molecules are bonded by Van der Waals forces, and they are usually amorphous or semi-crystalline in the solar cell active layer. On the other hand, the transfer of charges between molecules is governed by weak intermolecular coupling or hopping. As a result, the charge carrier mobilities are very low (typically $10^{-2}$ to $10^{-3} \mathrm{~cm}^{2} V^{-1} \mathrm{~s}^{-1}$ ), and strongly depend on the morphology of the bulk material [12].

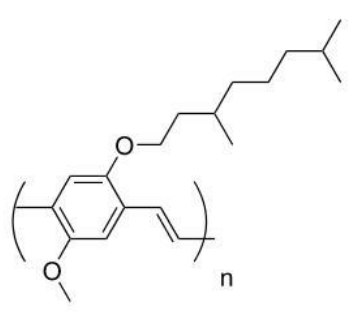

MDMO-PPV

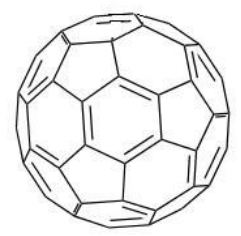

$\mathrm{C}_{60}$

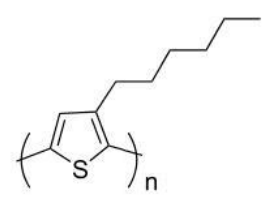

P3HT

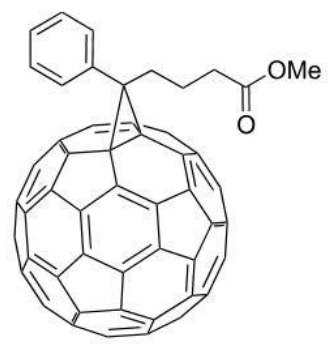

PCBM

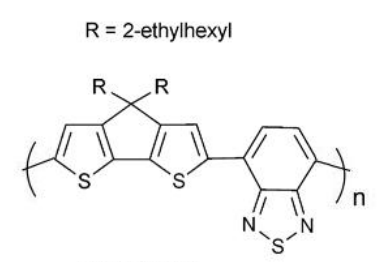

PCPDTBT

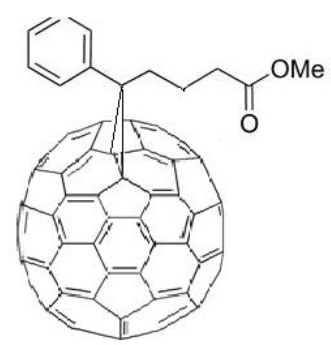

$\mathrm{PC}_{71} \mathrm{BM}$

Figure 1.4: Structure of M-PPV, $\mathrm{C}_{60}, \mathrm{P} 3 \mathrm{HT}, \mathrm{PCBM}, \mathrm{PCPDTBT}, \mathrm{PC}_{71} \mathrm{BM}$ [16-21]

Initially Organic Photovoltaics (OPVs) were dominated by M-PPV (poly[2-methoxy,5(20-ethyl-hexyloxy)-p-phenylene vinylene])/C60 [16-18], which was later on substituted by the better-processable and higher efficiency combination of P3HT/PCBM [19]. 
Nowadays, more new materials have been invented, such as PCPDTBT $/ \mathrm{PC}_{71} \mathrm{BM}$ [20.21], as shown in Figure 1.4 P3HT/PCBM had been the focus of OPVs research for the last decade. Our focus on P3HT/PCBM material system was not only to better understand its operation mechanism, but also to serve as references for various new material systems and device architectures.

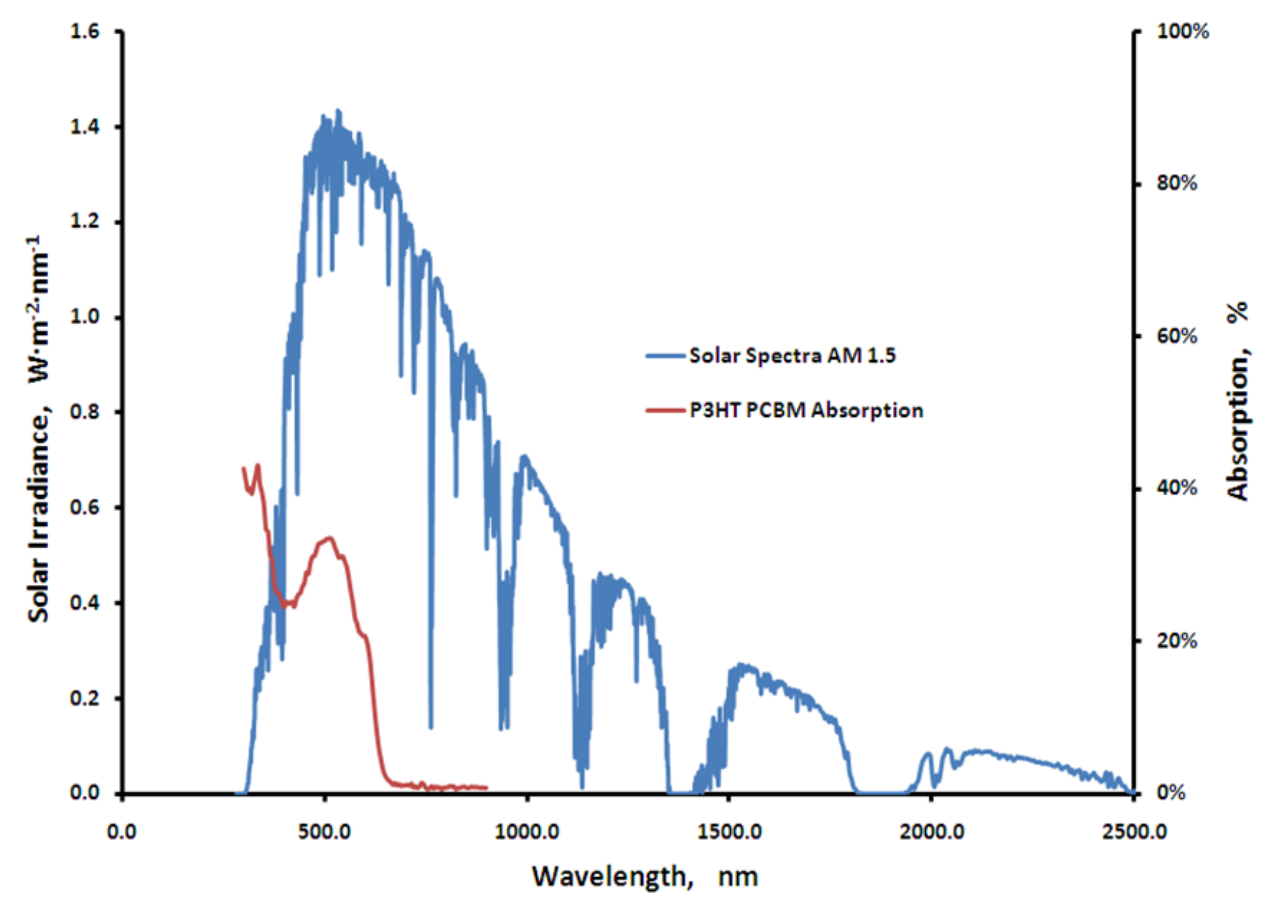

Figure 1.5: Solar emission spectrum (AM 1.5) $[1,2]$ and absorption spectrum of an 80 nm thick P3HT/PCBM blend film

Figure 1.5 shows the comparison of the solar emission spectrum (AM 1.5) and the absorption spectrum of an $80 \mathrm{~nm}$ thick P3HT/PCBM blend film. An $80 \mathrm{~nm}$ thick film will only absorb $20.1 \%$ of the solar spectra, mostly due to the $1.88 \mathrm{eV}$ band gap of P3HT. This means the efficiency limit of $80 \mathrm{~nm}$ thick P3HT:PCBM cell can not 
surpass $20.1 \%$ even for a $100 \%$ quantum efficiency case.

$$
\eta=\frac{\int A M 1.5 \times \text { Absorption } d \lambda}{\int A M 1.5 d \lambda} \approx 20 \%
$$

One could argue that $80 \mathrm{~nm}$ is too thin to achieve maximum absorption, the thickness of film can be increased to enhance absorption. However, $80 \mathrm{~nm}$ is the optimized thickness for P3HT:PCBM, with other considerations such as recombination. One could increase the active layer thickness, but the diffusion length of the carriers are limited. The thicker the layer is, the more likely recombination will occur, which limits the efficiency. The newly invented material combinations are optimized mainly in two aspects: decreasing the absorbing material's band gap to increase the absorption range to fully utilize the solar spectrum; increasing the diffusion length of the material for high absorption without sacrificing the active layer's thickness.

\subsubsection{Device Structure}

The general structure of an OSC device consists of a transparent substrate (glass, quartz, plastic), coated with a transparent electrode (indium tin oxide(ITO)), two layers of organic materials, with one as the electron donor and the other as the electron acceptor, and finally one top metal electrode. Control of blend morphology at the microscopic scale is critical for optimizing the power conversion efficiency of plastic solar cells based on blends of conjugated polymer with fullerene derivatives. One of the major advancements in device structure has been the introduction of bulk heterojunction structure (BHJ). Figure 1.6 shows the material distribution of a bilayer(left) and a bulk heterojunction(right) OSC. By co-depositing the donor and acceptor materials or mixing them in the solvent and then spin coating, a bulk heterojunction

structure was formed, which greatly enlarged the donor/acceptor interface and thus 
shortened the distance for electron hole pair to reach interface for disassociation.

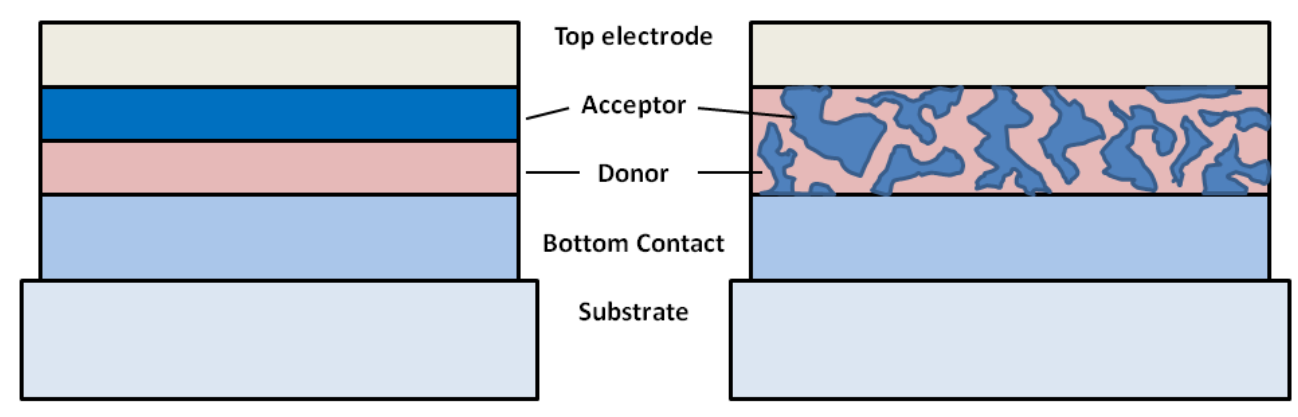

(a) Bilayer Structure

(a) Bulk Heterojunction

Figure 1.6: The structure of organic solar cells: bilayer (left),bulk heterojunction (right)

To form a BHJ structure, the donor and acceptor materials are blended in the solution and then spin-casted to form active layer. The morphology of the BHJ active layer, which is the packing of the molecules and the formation of domains of different compositions, is greatly affected by the processing conditions and the subsequent treatments. Many studies have shown that the morphology of the the active layer determines the device performance. There are several ways to control the blend morphology, such as different pre-deposition and post-deposition procedures, different solvent choices, slow drying of spin-coated films vs. quick drying, thermal annealing (annealing time and temperature, annealing in air or vacuum). All these different fabrication procedures will affect the formation of a phase-separated morphology with crystalline P3HT chains (or network) and PCBM domains and in all cases lead to differences in the photovoltaic device performance. For different fabrication processes, the experimental procedures have to be optimized to achieve better solar cell efficiency performance. 
Many techniques have been used to study the morphology of blend films, for example: atomic force microscopy, optical microscopy and Raman spectroscopy. It seems that the materials are not perfectly blended after the film formation. The PCBM tend to form little crystal domains, while the P3HT forms long and complex network. In order to explore the detailed composition variation of the film, variableangle spectroscopic ellipsometry (VASE) is used to characterize the film [22]. VASE is a non-invasive optical probe that monitors changes in the polarization state of light on reflection from a sample. It is a well-established technique to measure the optical constants of thin films, as well as concentration-depth profiles of composite films [23, 24]. The results of VASE examination of P3HT and PCBM distribution in the active layer are shown in Figure 1.7. The results show that there is a vertical segregation of donor and acceptor materials probably due to the difference in surface energy 22.

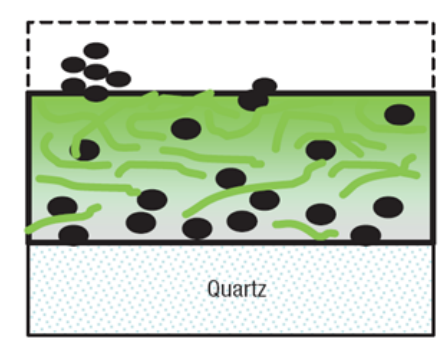

(a) before annealing

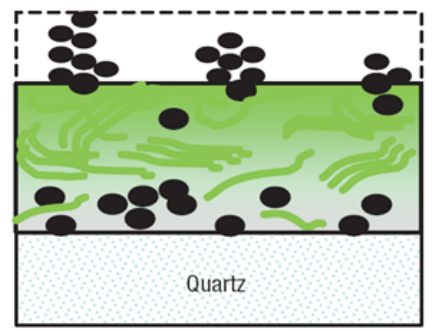

(b) after annealing

Figure 1.7: Schematic representations of the model used to fit the ellipsometry data, showing typical PCBM distributions (a) before and (b) after thermal annealing [22]

The invention of optical spacer [25] is another attempt to enhance the efficiency 
via altering the device structure.

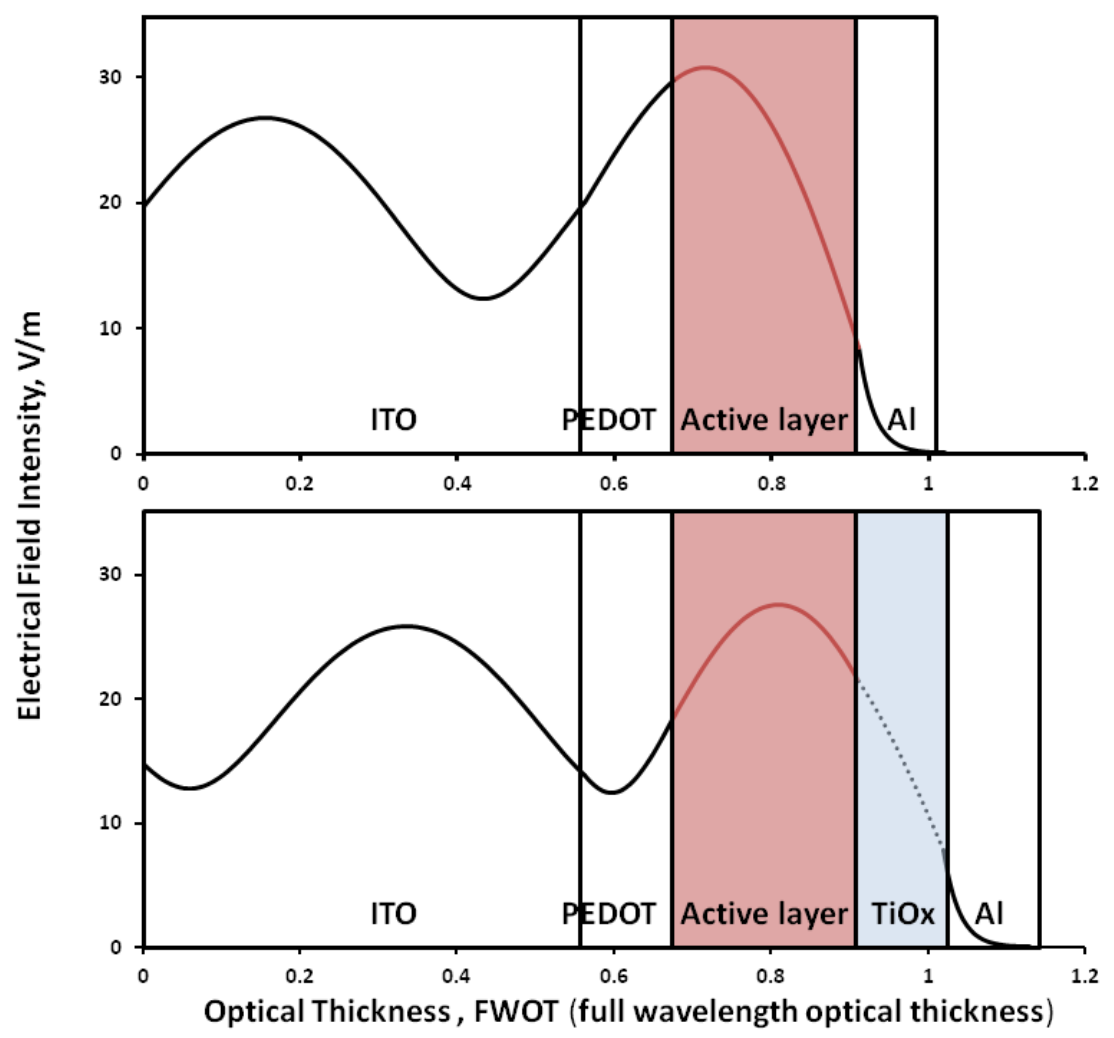

(a)

(b)

Figure 1.8: Electrical field intensity distribution in P3HT/PCBM solar cell device with (a) and without (b) $\mathrm{TiO}_{x}$ spacer

As shown in the Figure 1.8, $\mathrm{TiO}_{x}$ works as an optical spacer which shifts the electrical field peak into the active layer. The shift increases the total light intensity in the active layer by $50 \%$, which increases the device efficiency by up to $50 \%$. 


\subsubsection{Device Fabrication}

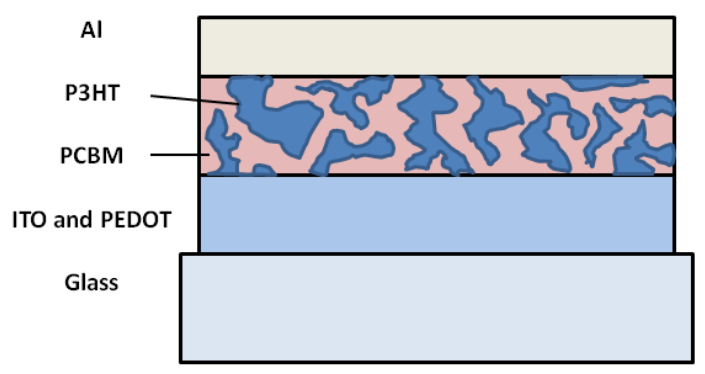

Figure 1.9: P3HT:PCBM solar cells structure

The device fabrication procedure varies for different OSCs. A typical P3HT:PCBM solar cell fabricating procedure is described below:

- (0) P3HT and PCBM were dissolved in chlorobenzene 24 hours before fabrication. The blend solution was 1 wt.\% in total, composed of a ratio of $45: 55$ of P3HT (provided by Sigma-Aldrich) to PCBM (provided by Nano-C).

- (1) The indium tin oxide (ITO)-coated glass substrate (provided by Delta Technologies) was first cleaned with acetone and isopropyl alcohol and subsequently dried by air.

- (2) Highly conducting PEDOT:PSS provided by H. C Starck was spin-casted (4000 rpm) from aqueous solution. The substrate was baked for 15 minutes at 
$110^{\circ} \mathrm{C}$ in air.

- (3) The blend solution was then spin-casted at $500 \mathrm{rpm}$ on PEDOT layer.

- (4) Then the sample was baked in a vacuum oven at $60{ }^{\circ} \mathrm{C}$ for 30 minutes.

- (5) An $80 \mathrm{~nm}$ thin Al layer was then deposited as the top electrode using electron beam vapor deposition.

- (6) Finally, the sample was annealed at $130{ }^{\circ} \mathrm{C}$ for 2 minutes in air. Pure P3HT and PCBM devices were fabricated similarly.

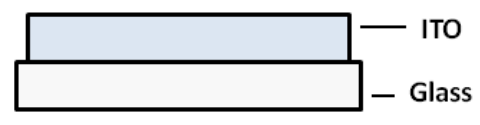

Step 1: glass with ITO as bottom contact

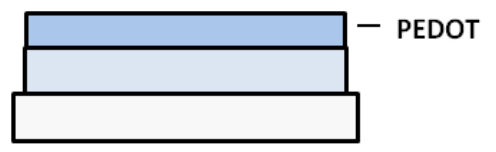

Step 2: spin coat PEDOT:PSS as a buffer layer

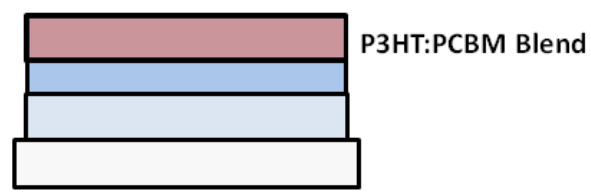

Step 3: spin coat blend solution to form

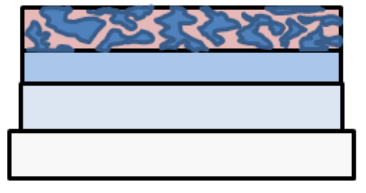

Step 4: slow drying of active layer

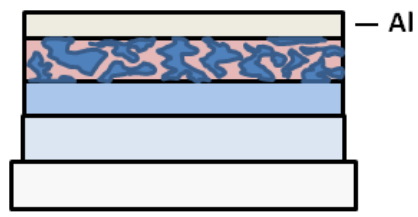

Step 5: deposit Al as top contact

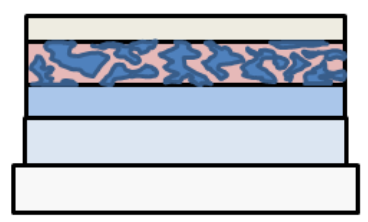

Step 6: final annealing

Figure 1.10: P3HT:PCBM solar cells fabricating procedures 


\subsubsection{Operation Mechanism}

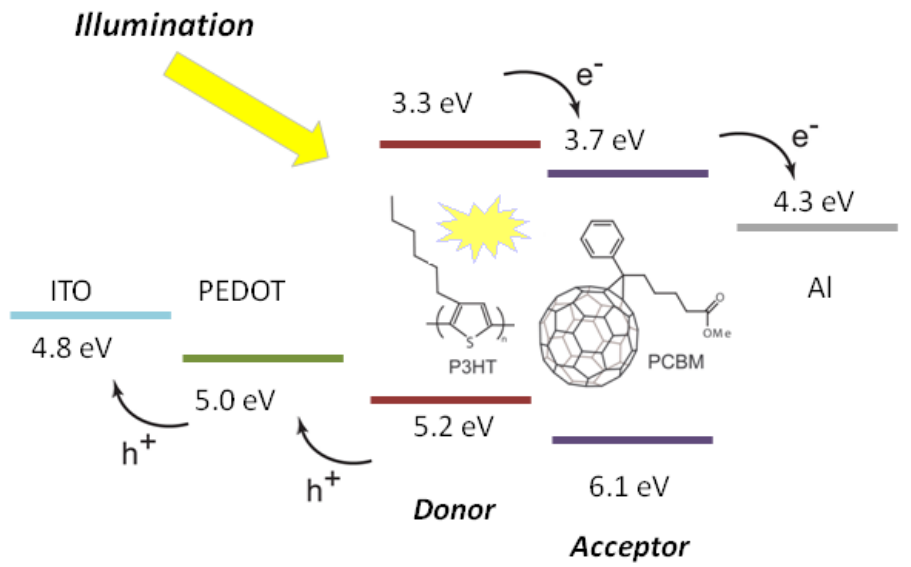

Figure 1.11: A general absorption and charge transport mechanism in an P3HT:PCBM OSC device

A general operation mechanism of an OSC device can be explained by the following five steps: (i)Light absorption (ii)Exciton generation and diffusion (iii)Exciton dissociation (iv)Charge transport (v)Charge collection.

(i)Light absorption: Photons absorbed by the molecules can form an exciton. For sufficient light absorption, the band gap of the molecules has to be small to cover the solar spectrum. However, a small band gap light absorbing material would waste the photon energy higher than its band gap. Another important parameter that 
needs to be taken into consideration is the light intensity distribution within the cell. For P3HT, the band gap is $1.88 \mathrm{eV}$, which will generate a maximum of 34.6 $\%$ efficiency due to the Shockley and Queisser limitation [7]. With other factors, such as absorption with a limited thickness, the number could drop to $20 \%$, or even lower if take into consideration of the charge transportation and collection loss. The thickness of different layers has to be optimized to ensure sufficient light absorption by the active layer.

(ii)Exciton diffusion: The exciton generated with the absorbed photon energy diffuses in the bulk before it decays or disassociates. The exciton has a diffusion length related to the exciton life time and diffusion coefficient, which is usually very short. This limits the thickness of a bi-layer organic solar cell, because if the bulk thickness is greater than the diffusion length, most exciton will decay to the ground state, and thus the device will suffer a low internal quantum efficiency. The bulk heterojunction design, which mixes the donor and acceptor materials together, greatly enlarges the donor acceptor interface, making it possible for both sufficient light absorption and electron hole pair dissociation.

(iii)Exciton dissociation: At the donor acceptor interface, due to different electron affinities of the two materials, the electron will be acquired by the one with a higher electron affinity, which is the acceptor. As the electrons and holes dissociate and captured by the acceptor and donor, electrons are now in the LUMO of the acceptor while the hole is located in the HOMO of the donor. The energy difference between the two levels: LUMO of the acceptor and HOMO of the donor is expected to determine the maximum open circuit voltage produced by the cell.

(iv)Charge transport. There is no highly ordered lattice in bulk organic materials. The overlap of the $\pi$ orbitals between nearby molecules determines the intermolecular 
charge transfers, or in other words, hopping. The weak bonding between molecules and the highly disorder morphology produces a low charge carrier mobility (typically $10^{-2}$ to $10^{-3} \mathrm{~cm}^{2} \mathrm{~V}^{-1} \mathrm{~s}^{-1}$ ) compared with highly ordered crystalline materials (typically $\left.>1 \mathrm{~cm}^{2} V^{-1} \mathrm{~s}^{-1}\right)$ 26]. Thermal annealing has been proved to be a great help in improving morphology of the bulk heterojunction devices and thus enhances the efficiency performance of the cells.

(v)Charge collection: Charge collection by the different electrodes is a complex process. Metal-organic and metal oxide-organic interface, have their own complex nature. Research has proven that a thin LiF layer between Al-organic interface will improve the $V_{O C}$ of the P3HT:PCBM devices, and an additional PEDOT:PSS (poly $(3,4$ - ethylenedioxythiophene) poly(styrene sulfonate)) layer on top of ITO will greatly enhance the efficiency performance [27]. Modification of the interface have been proven to improve the performance of the cell, yet more investigation is needed to understand the physics at these interfaces.

\subsubsection{Device Characterization}

Below is a typical current-voltage characteristic curve of an OSC device. The maximum power output point is defined as $P_{M A X}$, and maximum current density and voltage is defined as $J_{M A X}$ and $V_{M A X}$. Short circuit current $\operatorname{density}\left(J_{S C}\right)$ is the current density when the voltage across the device is zero, and open-circuit voltage $\left(V_{O C}\right)$ is the voltage when the current density in the device is zero. 


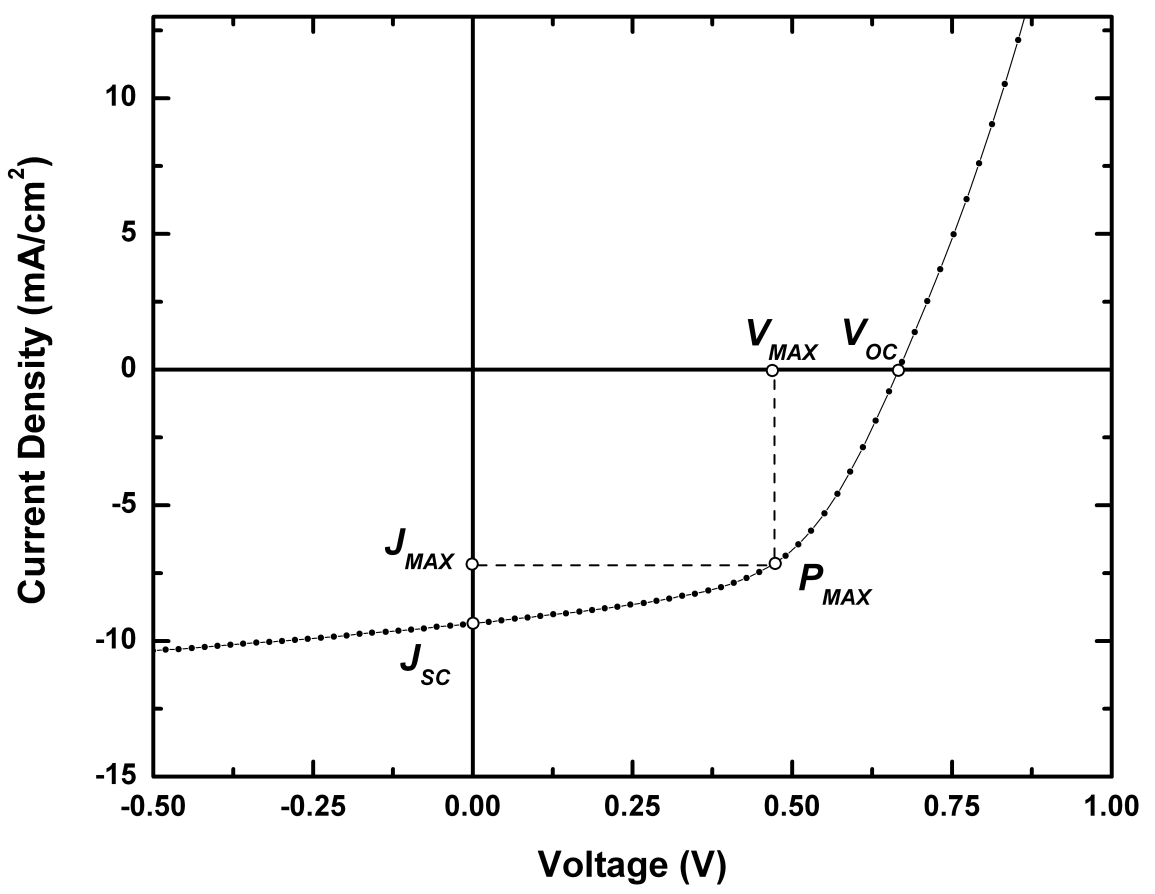

Figure 1.12: Typical J-V curves for a P3HT/PCBM OSC device under AM1.5 illumination with key performance parameters noted

The most important parameter of an OSC is the power conversion efficiency $(\eta)$, which represents the ability of the cell to convert light into electricity. Power conversion efficiency is defined by the following equation:

$$
\eta=\frac{P_{M A X}}{P_{I N}} \times 100 \%=\frac{\left|J_{M A X}\right| V_{M A X}}{P_{I N}} \times 100 \%=F F \frac{\left|J_{S C}\right| V_{O C}}{P_{I N}} \times 100 \%
$$

with the Fill Factor(FF) defined by:

$$
F F=\frac{\left|J_{M A X}\right| V_{M A X}}{\left|J_{S C}\right| V_{O C}} \times 100 \%
$$

From Equation 1.2, it is obvious that a high efficiency could be reached with higher $V_{O C}, J_{S C}$ and FF. $V_{O C}$ is simply one parameter which can be measured direct- 
ly. However, the origin of $V_{O C}$ is much more complex and still a subject of debate. $V_{O C}$ is affected by many factors. The most important ones are: (1)the HOMO and LUMO levels of the donor and acceptor [28] (2)the use of different anode or cathode materials and their contact with the active layer (3)operating environment(light intensity, temperature, etc.) and (4)morphology of the bulk. Detailed study is needed to better understand these factors and their influence on the $V_{O C} . J_{S C}$ or $J_{M A X}$ is the integral of photocurrent density at each wavelength, which relates directly to the External Quantum Efficiency(EQE). A higher $J_{S C}$ means more is absorbed, indicating the need of broad band absorption, which can be achieved by lowering the band gap or using tandem cells. $J_{S C}$ is also limited by the charge carrier mobility of the bulk material, as recombination is also an issue for power losses. FF is mostly affected by the series resistance of the cell. A low series resistance would help to increase the FF. These electrical parameters of OPVs need to be studied to help further enhance the efficiency.

\subsection{Thesis Outline}

This thesis is mainly about the investigation of the electrical properties of organic solar cells (OSC) to further enhance their power conversion efficiency. Chapter 2 is about the electrical conducting mechanism study via resistance measurements of the OSC device. Chapter 3 is the investigation of the origin of $V_{O C}$ through ultraviolet photoelectron spectroscopy $(U P S)$. Additional work includes: Chapter 4: study of thermal conductivity of organic materials; Chapter 5: Investigation of femtosecond laser interaction with fused silica.

In Chapter 2, the series resistance of poly (3-hexylthiophene-2,5-diyl) (P3HT) and $[6,6]$-phenyl C61-butyric acid methyl ester (PCBM) bulk heterojunction (BHJ) 
organic solar cells (OSC) has been investigated. The series resistance of thermal annealed and un-annealed devices with different active layer thickness is measured. The series resistance of the organic solar cells consists of the bulk resistance of the active layer and the specific contact resistance between the active layer and the electrode. The bulk resistance and contact resistance are extracted from the measured series resistance using the vertical transmission line model (TLM) method. By fabricating devices with different active layer thickness, a relationship of the series resistance and thickness is established, from which the bulk and the contact resistance is derived. Thermal annealing helps to reduce both the contact and the bulk resistance. The contact resistance drops by a factor of 2 , while the bulk resistance decreases by a factor of 8. Results have shown that for an annealed P3HT:PCBM device which has an active layer thickness of $85 \mathrm{~nm}$ (optimum thickness for high efficiency), $17 \%$ of the total series resistance attributed to contact resistance and bulk resistance contributed the rest $83 \%$. The resistance of pure PCBM devices increase linearly with thickness, while the increasing trend of the pure P3HT devices can be described as two different increasing regions. The metal-semiconductor interface plays an important role for the device performance. Capacitance study are designed to further understand the charge transport mechanism of organic/Al and organic/ITO interface. The capacitance data are explained using schottky diode model. The temperature dependence of capacitance is also measured and the peak position and the slope of the curve are found to vary with temperature.

In Chapter 3, the origin of $V_{O C}$ is investigated through ultraviolet photoelectron spectroscopy. The $\left(V_{O C}\right)$ of P3HT and PCBM organic solar cell devices was measured at temperatures ranging from $15{ }^{\circ} \mathrm{C}$ to $145{ }^{\circ} \mathrm{C}$. The temperature dependence of the vacuum shift and of the highest occupied molecular orbital (HOMO) energy level of 
P3HT and PCBM were measured by ultraviolet photoelectron spectroscopy (UPS) in the same temperature range. The temperature dependence of the absorption edge was also studied in the same temperature range to obtain the temperature variation of the optical band gap energy $\left(E_{g}\right)$. The lowest unoccupied molecular orbital (LUMO) can then be obtained by subtracting $\left(E_{g}\right)$ from HOMO. The measured $V_{O C}$ of the devices showed a clear decreasing trend with the increased operating temperatures and the total decrease is found to be about $0.1 \mathrm{~V}$. However, by utilizing the measured values of the HOMO for the P3HT (donor) and LUMO for the PCBM (acceptor), the calculated values of $V_{O C}$ and its temperature dependence show an increasing trend with temperatures. The calculated values of $V_{O C}$ do not agree with the measured $V_{O C}$ values. This is a clear indication that the expression (HOMO - LUMO) - exciton binding energy does not hold, and that other factors are impacting the value of $V_{O C}$.

Chapter 4 discusses the thermal conductivity of organic materials. The thermal conductivities of P3HT, PCBM and P3HT:PCBM blend are measured by time domain thermoreflectance. Thermal conductivities vary from $0.031 \pm 0.005 \mathrm{~W} \mathrm{~m}^{-1} \mathrm{~K}^{-1}$ for pure PCBM to $0.227 \pm 0.014 \mathrm{~W} \mathrm{~m}^{-1} \mathrm{~K}^{-1}$ for pure P3HT near room temperature and exhibit minimal temperature dependence across the range 319 to $396 \mathrm{~K}$. Thermal conductivities of PCBM are less than $0.030 \pm 0.003 \mathrm{~W} \mathrm{~m}^{-1} \mathrm{~K}^{-1}$ at room temperature, much lower that the thermal conductivities of P3HT, possibly due to the molecular tails on the fullerene moieties which are responsible for lowering both the apparent sound speeds and the characteristic vibrational frequencies. Thermal conductivities of blend films follow a rule of mixtures and no percolation threshold is found. Thermal annealing of blend films has a variable effect on thermal conductivity. Finally, the thermal conductivities of P3HT films do not vary with changes in film thickness from 77 to $200 \mathrm{~nm}$. 


\section{Chapter 2}

\section{Charge Transport Mechanism Study}

\subsection{Statement of the Problem}

Organic semiconductors can be broadly classified into two categories: small molecules and polymers. In each case, various materials have been designed over the years that preferentially transport holes or electrons. The fullerene derivatives, are generally exploited as n-type materials, while conjugated polymers are generally exploited as p-type materials. In the P3HT:PCBM organic solar case, PCBM is the small molecule and $\mathrm{P} 3 \mathrm{HT}$ is the polymer. One of the key quantity that characterizes charge transport is the carrier mobility. The charge mobility is influenced by many factors including molecular packing, disorder, presence of impurities, temperature, electric field, chargecarrier density, size/molecular weight, and pressure. Efficient charge transport in solar cells not only requires the charges to be able to move from molecule to molecule and not be trapped or scattered but also to rely on efficient collection of the charge carriers through electrodes. Charge mobilities can be determined experimentally by various 
techniques, such as Time-of-Flight (TOF) [29], Field-Effect Transistor Configuration (FTC) 30 and the space-charge-limited-current (SCLC) method [31].

In the actual device case, charge carrier transport does not solely rely on the values of charge mobilities, but also depend on other factors such as charge carrier life time, charge carrier injection and collection by the electrodes, charge carrier recombination at layer interface and general leakage through shunt resistance. Results from methods that measure over macroscopic distance often take into consideration of impurity level and the ordering of the material, while methods that measure mobilities over microscopic distances are less dependent on these characteristics. Therefore, it would be improper to evaluate a solar cell's charge transport efficiency through measuring just the charge carrier mobility of the organic material. This dissertation will not try to focus all this studies of the impact of these different factors on charge transport in organic semiconductors on the micro-scale. Rather, the goal here is to focus on the macro-scale at the device level, by measuring the resistance. This methodology of using the resistance to evaluate the P3HT:PCBM solar cells's charge transport properties can be extended to other solar cell material systems.

The power conversion efficiency of a solar cell depends on the $J_{S C}, V_{O C}$ and the FF. It is well known that a high series resistance reduces the fill factor and thus reduces cell efficiency 32 34. A typical multi-crystalline silicon solar cell has a series resistance of less than $1 \Omega \mathrm{cm}^{2}$ [35], while a P3HT PCBM organic solar cell has a series resistance of around $20 \Omega \mathrm{cm}^{2}\left[36\right.$, and the loss due to $I^{2} R$ is around $30 \%$ of the total output power. In order to reduce series resistance to enhance efficiency, the series resistance of organic solar cells needs to be better understood. Rakhshani has developed a method of fitting dark I-V characteristics of CdTe/CdS solar cells for series resistance [37. The TLM model is a well-established method to characterize contact resistance in 
semiconductor devices [38, 39]. By varying the active layer thickness, Aernouts et al. extracted the bulk and contact resistance from series resistance of MDMO-PPV: PCBM solar cells under illuminated (AM 1.5) condition [40]. It has been shown that thermal annealing can be used to reduce series resistance, which can lead to the enhanced performance of organic solar cells 44, 42].

Investigation of the series resistance for annealed and un-annealed organic solar cell devices has been conducted and the contact and bulk resistance has been extracted. It turned out that bulk resistance contributed the most to the total series resistance, while annealing helped to reduce bulk resistance more than it helped to reduce contact resistance. The research work of this study has been published in Journal of Solar Energy Materials and Solar Cells [43]. To further understand the charge transport mechanism, the conduction mechanism in each component(P3HT, PCBM) have been carried out. A study of the organic/Al and organic/ITO interface has been taken, and the research work of this study has been published in the proceeding of the Photovoltaic Specialists Conference (2012 38th IEEE PVSC) [44].

\subsection{Experiments and Data Analysis}

\begin{tabular}{|c|}
\hline Epoxy Resin \\
\hline Al $80 \mathrm{~nm}$ \\
\hline P3HT:PCBM $80 \mathrm{~nm}$ \\
\hline PEDOT:PSS $40 \mathrm{~nm}$ \\
\hline ITO $140 \mathrm{~nm}$ \\
\hline \\
Glass $0.9 \mathrm{~mm}$ \\
\hline
\end{tabular}

Figure 2.1: Device structure of P3HT:PCBM solar cell 
P3HT:PCBM solar cells (Figure 2.1) were prepared according to the following procedure: P3HT and PCBM were dissolved in chlorobenzene for 24 hours before fabrication. The density of the blend solution was 1 wt.\% in total. It was composed of a ratio of 45 : 55 of P3HT (provided by Sigma-Aldrich) to PCBM (provided by Nano-C). The indium tin oxide (ITO)-coated glass substrate (provided by Delta Technologies) was first cleaned with acetone and isopropyl alcohol and subsequently dried by air. Highly conducting PEDOT:PSS provided by H. C Starck is spin-casted (4000 rpm) from aqueous solution. The substrate was baked for 15 minutes at 110 ${ }^{\circ} \mathrm{C}$ in air. The blend solution was then spin-casted at $500 \mathrm{rpm}$ on PEDOT layer. Then the sample was baked in a vacuum oven at $60{ }^{\circ} \mathrm{C}$ for 30 minutes. An $80 \mathrm{~nm} \mathrm{Al}$ layer was then deposited as the top electrode using electron beam vapor deposition. Finally, the sample was annealed at $130{ }^{\circ} \mathrm{C}$ for 2 minutes in air. To keep the device from degradation, a layer of epoxy resin is coated to encapsulate device. Pure P3HT and PCBM devices were fabricated similarly. In order to prevent the solar cell from degradation within hours. An additional epoxy resin coating was then apply to the solar cell surface. Figure 2.2 shows the efficiency comparison of devices with and without epoxy resin coating. It is obvious that an additional epoxy resin coating which sealed the cell could prevent it from degradation.

In order to study the series resistance, we measured the current-voltage (I-V) characteristics using a Keithley 2611 source meter. Series resistances were then extracted from the dark I-V measurements. The methodology of extracting series resistance from dark I-V measurements will be discussed later. To extract the contact resistance and bulk resistance from series resistance, we fabricated devices with different active layer thickness by using different spin speeds. The contact resistance and bulk resistances were then obtained by linear fitting the data of series resistances versus active 


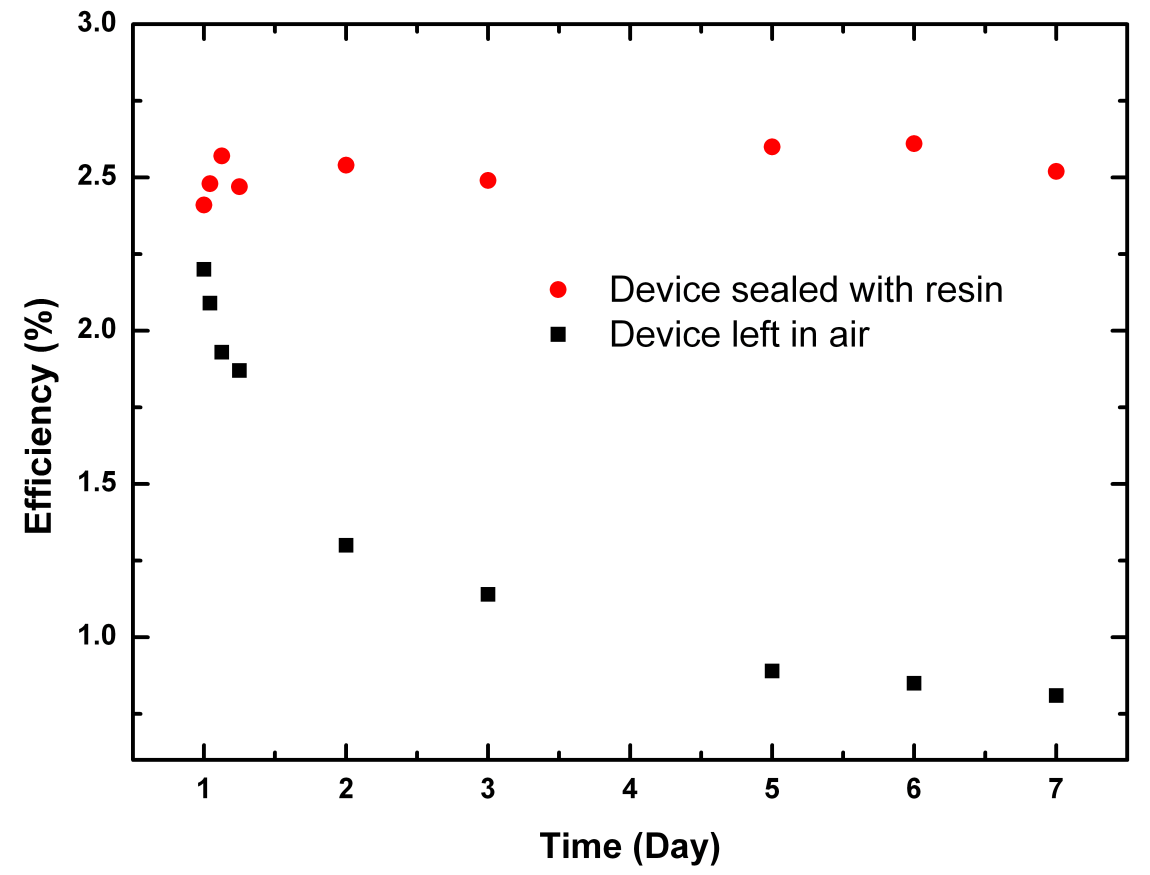

Figure 2.2: Efficiency comparison of devices with and without epoxy resin coating, both devices are left in air with room light on for one week

layer thickness. To study the effect of annealing on contact resistance and bulk resistance, we measured the series resistance for both the un-annealed and the annealed devices. Current-voltage characteristics were measured for the un-annealed devices. The un-annealed devices were then annealed at $130{ }^{\circ} \mathrm{C}$ for 2 minutes. Current-voltage characteristics were then again measured for these annealed devices. The purpose of using the same devices for both the un-annealed and the annealed conditions was to eliminate other variables for a more precise study of the annealing effect on contact resistance and bulk resistance.

Extraction of series resistance from I-V measurements under dark was done using one diode model of organic solar cell as given below:

$$
I=I_{L}-I_{0}\left[e^{\frac{q\left(V-I R_{s}\right)}{n k T}}-1\right]-\left(V-I R_{s}\right) / R_{s h}
$$


$I_{L}$ is photocurrent under illumination; $I_{0}$ is the reverse saturation current; $R_{s}$ is the series resistance; $R_{s h}$ is the shunt resistance; $n$ is the ideal factor; $k$ is Boltzmann constant; $T$ is temperature. The corresponding circuit model is shown in Fig. 2.3.

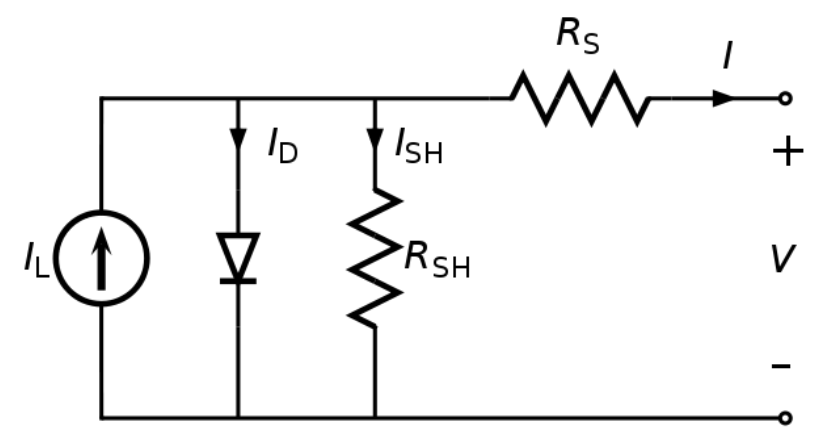

Figure 2.3: Equivalent circuit model of solar cells

With no illumination, the photocurrent is zero and we assume that shunt resistance is sufficiently high to eliminate the last term in Equation 2.1. Therefore, the dark $\mathrm{I}-\mathrm{V}$ characteristic can be expressed as

$$
I=I_{0}\left[e^{\frac{q\left(V-I R_{s}\right)}{n k T}}-1\right]
$$

The voltage can be expressed as a function of current as

$$
V=\frac{n k T}{q} \ln \left(\frac{I}{I_{0}}+1\right)+I R_{s}
$$

From this expression the current derivative of voltage can be written as

$$
\frac{d V}{d I}=\frac{n k T}{q} \frac{1}{\frac{I}{I_{0}}+1} \frac{1}{I_{0}}+R_{s}
$$

In the high current region, the total current is much higher than the reverse saturation current $\left(I \gg I_{0}\right)$. Then, Equation 2.4 becomes 


$$
I \frac{d V}{d I}=I R_{s}+\frac{n k T}{q}
$$

Under these assumptions $I d V / d I$ is linearly dependent on I. Therefore, the series resistance can be easily extracted from the slope by a linear fit in the high current region. A typical dark IdV/dIvs.I characteristic curve is shown in Equation 2.4.

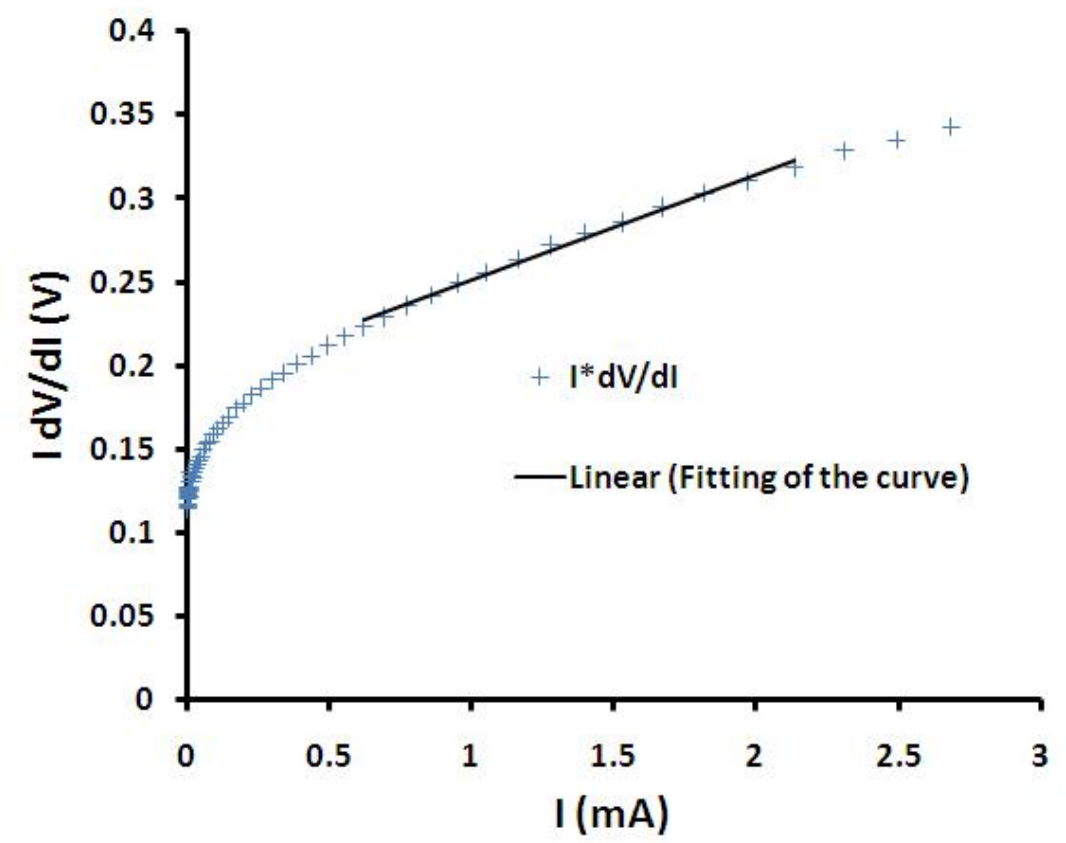

Figure 2.4: The I dV/dI vs. I curve for an organic solar cell

The specific series resistance between two contacts can be expressed by the following equation

$$
R_{S}=R_{\text {bulk }}+R_{\text {contact }}=\rho_{\text {bulk }} \times d+R_{\text {contact }}
$$

$R_{\text {bulk }}\left(\Omega c m^{2}\right)$ is the bulk resistance of the active layer itself. $R_{\text {contact }}\left(\Omega c m^{2}\right)$ is the specific contact resistance between the active layer and the electrode. $\rho_{b u l k}(\Omega \mathrm{cm})$ is the resistivity of the active layer and $d(\mathrm{~cm})$ is the thickness of the active layer. From 
the above equation, one can see that by fabricating devices with different active layer thickness, a relationship of the series resistance versus thickness can be obtained and the contact resistance can be derived.

\subsection{Resistance of P3HT:PCBM solar cells}

Samples with different active layer thickness were fabricated. Each sample had 8 individual devices. The thickness of the active layer was measured by an atomic force microscope (AFM).

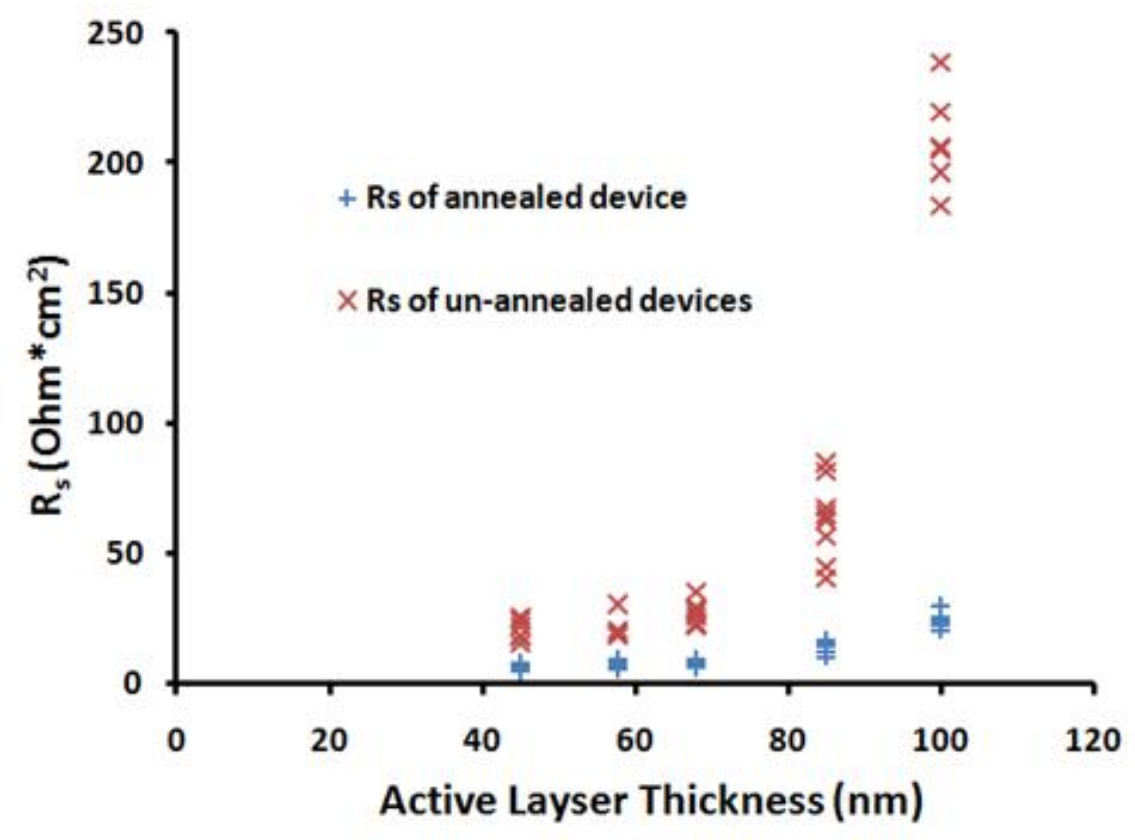

Figure 2.5: $R_{S}$ of P3HT:PCBM organic solar cells with different active layer thicknesses of $45 \mathrm{~nm}, 58 \mathrm{~nm}, 68 \mathrm{~nm}, 85 \mathrm{~nm}$ and $100 \mathrm{~nm}$. The measurements were conducted in dark.

From Figure 2.5, we can see that the $R_{S}$ value decreased after annealing for all active layer thicknesses. The thicker the active layer, the larger the reduction. For both the un-annealed and the annealed devices, $R_{S}$ increased rapidly for thickness $>80$ 
nm. This can be explained by the diffusion length of P3HT:PCBM solar cells. When the active layer is thicker than the typical diffusion length of carrier in P3HT:PCBM solar cells, the probability of recombination will increase rapidly. This effect will be manifested as less current in the devices, which will result in higher $R_{S}$.

To extract the contact and the bulk resistances from the total series resistance, devices with active layer thinner than $80 \mathrm{~nm}$ were chosen. The results are shown in Figure 2.6.

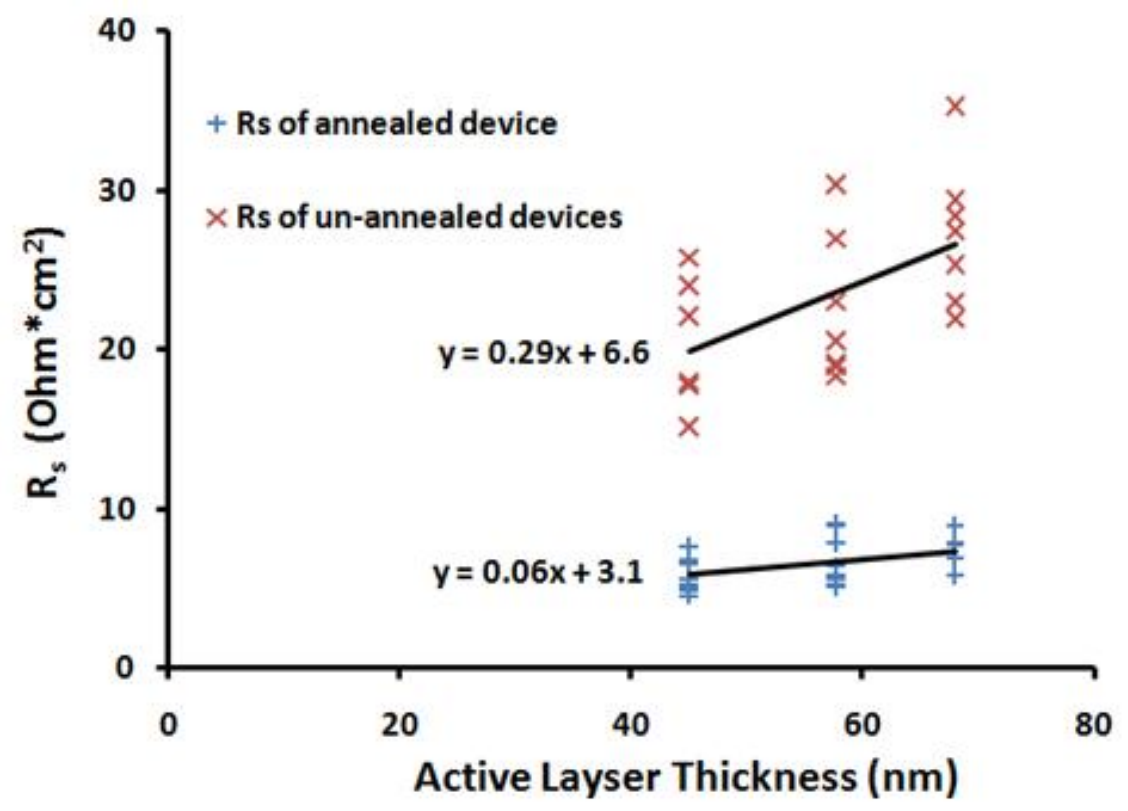

Figure 2.6: Linear fitting to $R_{S}$ versus active layer thickness.

For the annealed devices, the specific contact resistance was calculated as 3.1 $\Omega \mathrm{cm}^{2}$ and for the un-annealed devices, the specific contact resistance was $6.6 \Omega \mathrm{cm}^{2}$. This shows that the annealing helps to decrease contact resistance but the magnitude of the change is only a factor of 2. For an annealed P3HT: PCBM device which has an active layer thickness of $85 \mathrm{~nm}$ chosen for the highest efficiency, the average series resistance was $18 \Omega \mathrm{cm}^{2}$. Therefore, contact resistance only contributes about $17 \%$ 
to the total series resistance while bulk resistance is the primary component of series resistance. As the series resistance is $126 \Omega \mathrm{cm}^{2}$ for un-annealed $85 \mathrm{~nm}$ thick devices, by subtracting the contact resistance, we find that annealing causes the bulk part of the series resistance to drop from $120 \Omega \mathrm{cm}^{2}$ to $15 \Omega \mathrm{cm}^{2}$, which is a factor of 8 , a much larger relative change than that observed for the contact resistance.

The effect of thermal annealing on P3HT:PCBM solar cells is a complex process. Both bulk and contact resistance decreased due to thermal annealing. As to bulk resistance, the decrease can be linked to the improvement of nanoscale morphology which is mainly due to the reordering of P3HT molecular chains. This is due to the increased crystallinity of P3HT, which helps to improve the charge carrier mobility of the P3HT and thus provides lower bulk resistance. Thermal annealing has also been shown to decrease contact resistance for organic solar cells. Ma et.al. have reported that solar cell device results obtained by annealing prior to top electrode deposition showed a clear decrease of efficiency compared with the results obtained by annealing after the deposition of top electrode. Using "sticky tape" technique, their AFM image showed a rougher surface of the interface of bulk material and Al electrode, which implies stronger interfacial adhesion, and stronger adhesion provided lower contact resistance. Studies have also shown that the formation of metal-polymer bonds (C-Al or $\mathrm{C}-\mathrm{O}-\mathrm{Al}$ bonds) and $\mathrm{Al}$ diffusion could also contribute to the decrease of contact resistance due to thermal annealing.

The current-voltage characteristics of organic solar cells are governed by two basic processes: carrier injection in the bulk material by the electrodes and charge transport in the bulk material [32,45]. In general, the injection process itself includes two processes: one is the Schottky emission process due to thermionic emission; the other is Poole-Frenkel emission due to field-enhanced thermal excitation of trapped 
charges and charge tunneling (Fowle-Nordheim tunneling) from the metal contact into the HOMO and LUMO level of the polymer. Carriers injected by the electrode have to overcome or tunnel through the barrier of the schottky junctions formed at metal-organic interface. In our case, these barriers are formed at the PEDOT-P3HT interface and the PCBM-Al interface, which are all small barriers (less than $0.3 \mathrm{eV}$ ) and at room temperature, they will not dominate the I-V characteristic. This is consistent with our reported low contact resistance values compared to series resistance value,

Once the charge carriers are injected, their transport through the polymer layer towards the opposite electrode is determined by the conduction properties of the material itself. The transport in bulk is mainly explained using Ohmic conduction at low voltages due to thermally excited carriers hopping from one isolated state to the next and the space-charge-limited current (SCLC) due to carriers injected into the polymer from the contacts [32]. In the P3HT:PCBM solar cell, P3HT and PCBM form the percolated paths, and the charge carrier transport through these paths. The holes are supposed to flow through P3HT channels and electrons through the PCBM channels 46]. The transport of carriers in these separated channels is limited by their own mobility and the total current will be limited by the one with lower mobility value, which is P3HT in our case. Generally, the charge carrier mobility in the organic polymers is very low. Low charge carrier mobility is related to structural disorder. In fact, as with inorganic amorphous semiconductors, conduction in such relatively disordered materials is mostly a function of "mobility gaps" [47] with phonon-assisted hopping, polaron-assisted tunneling, etc. between localized states. However, the interaction between P3HT and PCBM molecules cannot be simply neglected. The electrons and holes recombination is very likely to happen during the 
separated transport process. And if the bulk material was too thick, most carriers will end up recombine before they get to the electrode. As shown in the devices with active layer thicker than $80 \mathrm{~nm}$, the total resistance went up exponentially. This is due to the charge carrier recombination effect.

\subsection{Resistance of Pure P3HT and PCBM}

To further investigate the conduction mechanism of P3HT/PCBM OSCs, the conductivity of pure P3HT and PCBM was measured.

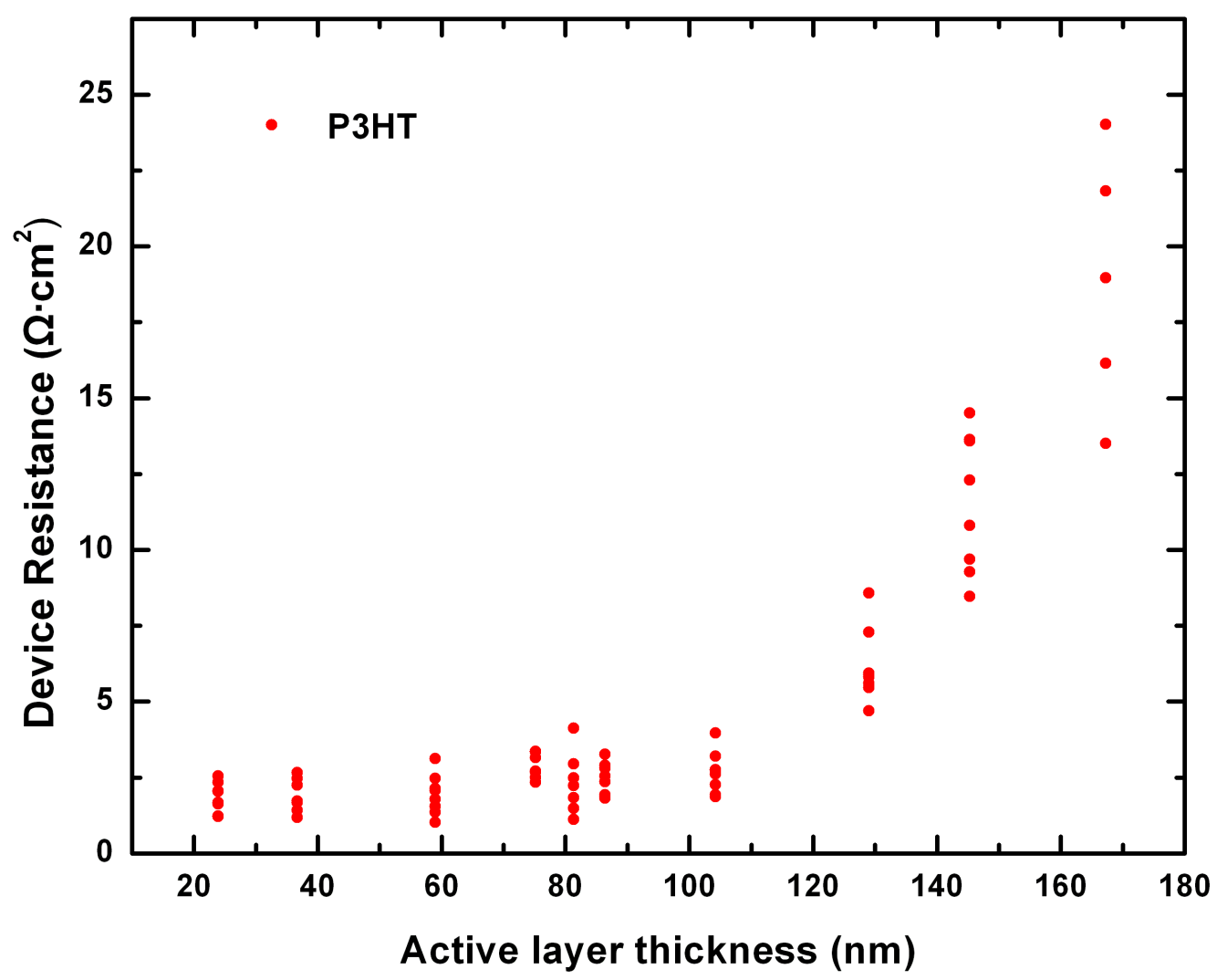

Figure 2.7: $R_{S}$ of P3HT device(ITO/P3HT/Al) with different P3HT layer thicknesses. 
Fig 2.7 shows the resistance of pure P3HT device. The device geometry is I$\mathrm{TO} / \mathrm{P} 3 \mathrm{HT} / \mathrm{Al}$, and they were all annealed at $130{ }^{\circ} \mathrm{C}$ for $2 \mathrm{mins}$ in air. The resistance increases with thickness of P3HT and shows two increasing trend. This can be explained by the charge carrier recombination effect. For active layer thicker than 100 nm, most charge carriers will end up recombining instead of being collected by the electrode. The contact resistance of pure P3HT device is $1.9 \Omega \mathrm{cm}^{2}$.

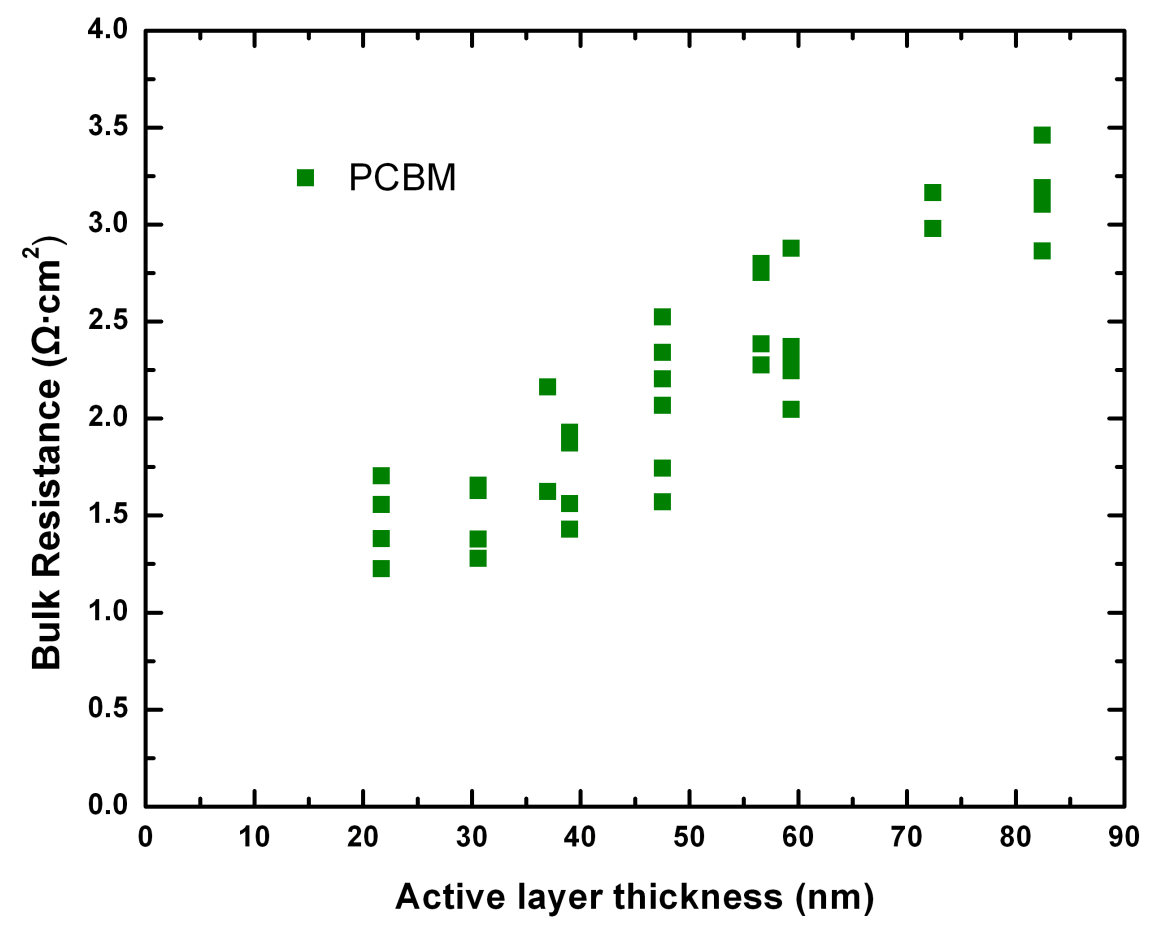

Figure 2.8: $R_{S}$ of PCBM device (ITO/PEDOT/PCBM/Al) with different PCBM layer thicknesses.

Figure 2.8 is the resistance of pure PCBM device. The device geometry is I$\mathrm{TO} / \mathrm{PEDOT} / \mathrm{PCBM} / \mathrm{Al}$, and they are all annealed at $130{ }^{\circ} \mathrm{C}$ for $2 \mathrm{mins}$ in air. The PEDOT is used here to prevent the shorting of the two electrodes. A steady increase of resistance with thickness is observed. Due to the limitation of PCBM solubilities 
in chlorobenzene, the most thick film obtained was around $85 \mathrm{~nm}$.

The series resistance of both P3HT and PCBM devices show a very low value (less than $5 \Omega \mathrm{cm}^{2}$ ) for devices with active layer thinner than $100 \mathrm{~nm}$. The resistance of P3HT and PCBM show an increasing trend with thickness. The resistance of pure PCBM devices increases linearly with thickness. The increasing trend of the pure P3HT devices can be described as two different increasing regions, mainly due to the recombination effect.

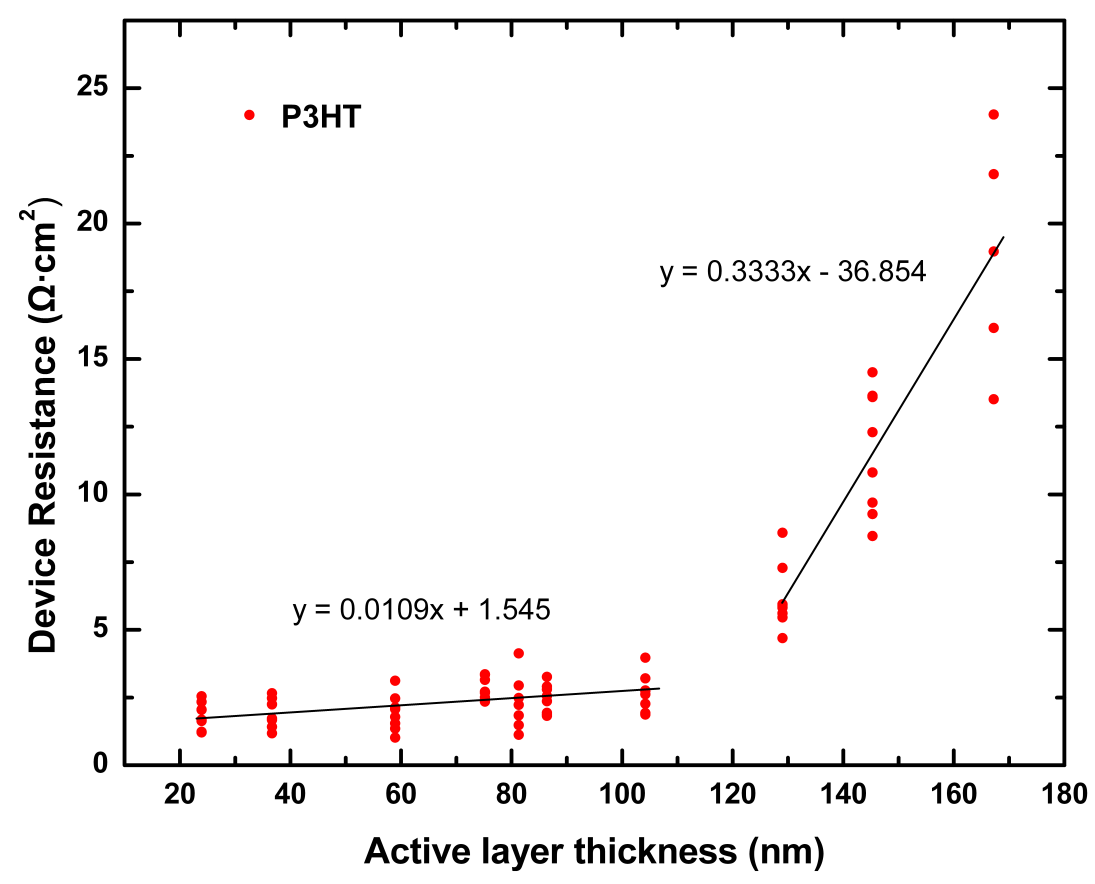

Figure 2.9: Curve fitting for P3HT devices (ITO/P3HT/Al) with different active layer thicknesses.

As shown in Figure 2.9, the increasing trend of P3HT resistance can be divide into two region with different slopes. For deice thickness below $110 \mathrm{~nm}$, the slope 
is low; for device thicker than $120 \mathrm{~nm}$, the slope suddenly increases. This can be explained by the limited diffusion length of P3HT. When the thickness of the active layer is within the diffusion length, the recombination of carriers are limited and the resistance reflects the resistivity of P3HT under low transport loss condition; when the thickness of the active layer surpasses the diffusion length, the recombination begins to dominate. The more charge carriers end up recombining, the less charge carriers are collected by the electrode, and thus the resistance increases dramatically.

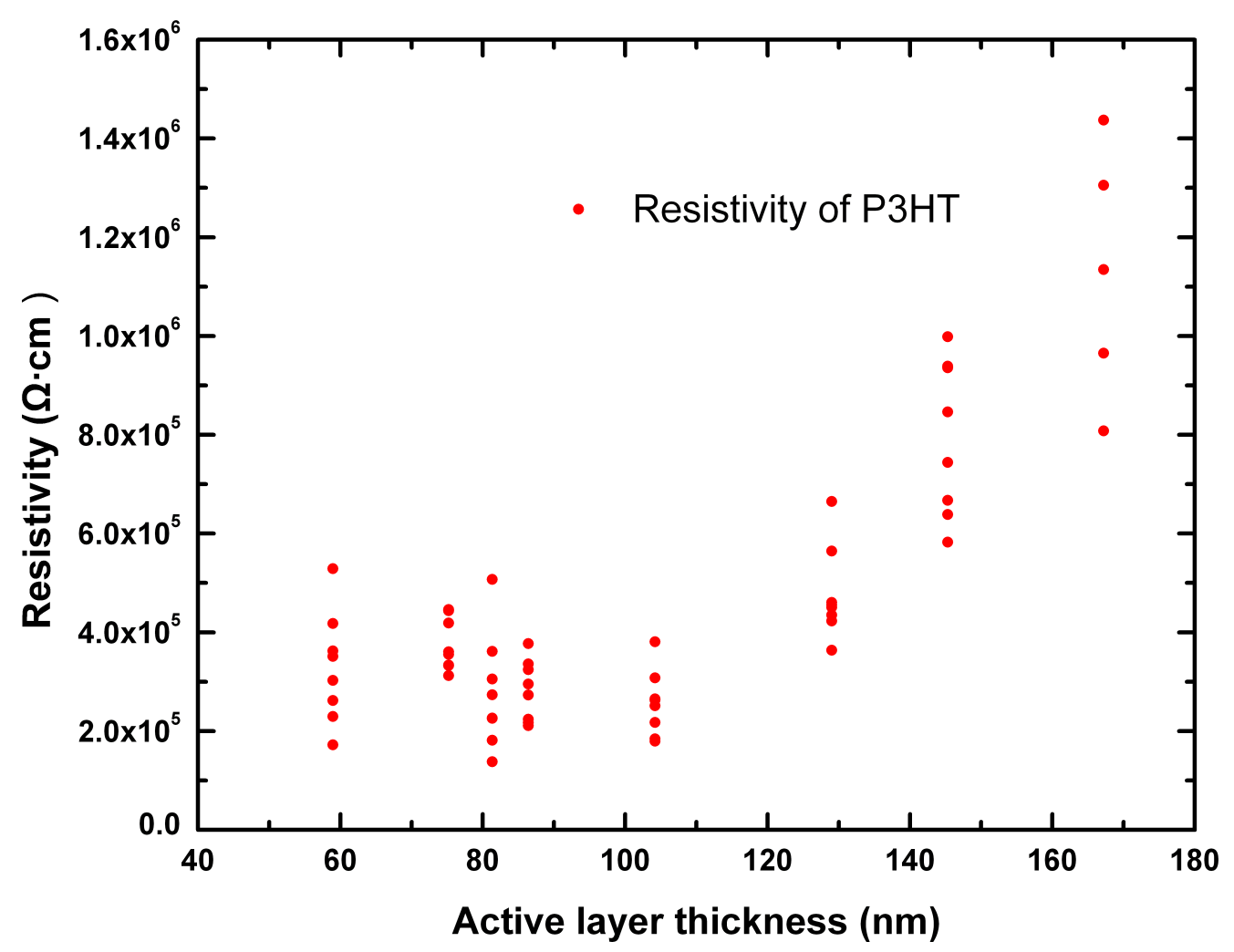

Figure 2.10: Reisitivity of P3HT device (ITO/P3HT/Al) with different P3HT layer thicknesses.

The $120 \mathrm{~nm}$ cross point can more easily be seen on the P3HT resistivity diagram as shown in Figure 2.10. By subtracting the contact resistance and taking into con- 
sideration the thickness of the P3HT layer, the resistivity of P3HT can be calculated. When the active layer is thinner than $120 \mathrm{~nm}$, the resistivity of P3HT does not vary, which is normal, because resistivity should not vary with thickness of the material for most crystals. However, this rule does not apply in the conjugate polymer case. For active layer thicker than $120 \mathrm{~nm}$ cases, the resistivity grows rapidly. The same explanation can be applied here. That is the rapid increase of resistivity is due to the dominating recombination effect.

On the other hand, the contact resistance of pure PCBM device is $0.9 \Omega \mathrm{cm}^{2}$, less than the value of P3HT which is $1.9 \Omega \mathrm{cm}^{2}$. Both contact resistances contribute a big fraction in series resistance (1 to $4 \Omega \mathrm{cm}^{2}$ for device with active layer thinner than $100 \mathrm{~nm}$ ), indicating the existence of charge carrier barrier at the interface between the electrodes and the organic materials and the interface of the active layer and functional layers.

\subsection{Conclusions and Future work}

The summary of our findings of the resistance measurements:

- We have shown a the resistance level of a P3HT:PCBM solar cell device is around 10 to $20 \Omega \mathrm{cm}^{2}$. The values are mainly depend on the active layer thickness.

- We have extracted the two components of the series resistance: which are bulk resistance and contact resistance. Bulk and contact resistance consist of $80 \%$ and $20 \%$ of the series resistance, for an annealed P3HT: PCBM device which has an active layer thickness of $85 \mathrm{~nm}$ chosen for the highest efficiency. Compared with the bulk resistance, the contact resistance is relatively smaller but still not 
negligible.

- Thermal annealing of the devices reduces both contact resistance and bulk resistance: a factor of 8 for the bulk resistance, and a factor of 2 for the contact resistance(85 $\mathrm{nm}$ device). The factors depend on the active layer thickness.

- The contact resistance of pure PCBM device is around $1 \Omega \mathrm{cm}^{2}$, less than the value of P3HT which is around $2 \Omega \mathrm{cm}^{2}$. Both materials' bulk resistance is less than $5 \Omega \mathrm{cm}^{2}$ for thickness less than $80 \mathrm{~nm}$.

- In both solar cell device and pure P3HT case, for films thicker than $80 \mathrm{~nm}$, the bulk resistance increased rapidly, suggesting a rapid increase of charge carrier recombination rate when the active layer thickness are beyond $80 \mathrm{~nm}$.

Series resistance has a big impact on fill factor which directly affects the efficiency. As to the P3HT:PCBM solar cell, Jonathan et al. have shown by modeling that, for $R_{s}=100 \Omega c m^{2}, \eta=1.0 \% ; R_{s}=10 \Omega \mathrm{cm}^{2}, \eta=4.3 \% ; R_{s}=1.4 \Omega \mathrm{cm}^{2}, \eta=5.2$ $\% ; R_{s}=0 \Omega \mathrm{cm}^{2}, \eta=5.3 \%$ [8]. Noted that the modeling result is based on the same diode equation (Equation 2.1) as we used in this thesis. The photo current, the reverse saturation current, the shunt resistance and the ideal factor are set to experimentally measured values for P3HT:PCBM solar with $\eta=5 \%$. It is obvious that for P3HT:PCBM solar cell, the current value of 10 to $20 \Omega \mathrm{cm}^{2}$ is still too high. A boost of $1 \%$ efficiency could be realized if we manage to decrease the series to the $1 \Omega \mathrm{cm}^{2}$ level. It can also be seen that if $R_{s}$ is smaller than $1 \Omega \mathrm{cm}^{2}$, further reduction of $R_{s}$ inducing improvement on efficiency is negligible, based on the current P3HT:PCBM solar cell performance.

The decrease of series resistance has to come from the reduction of both bulk resistance and contact resistance. As we have shown in conclusion (2), bulk and 
contact resistance consists of $80 \%$ and $20 \%$ of the series resistance. The major reduction has to come from the bulk resistance part. We have shown that thermal annealing greatly reduces bulk resistance. Basically what thermal annealing does is altering the morphology of the active layer. In other words, the reordering of molecular: chains of P3HT relaxes and extends and the PCBM molecules closely packed to the chains. Other techniques that currently have been used to control the morphology are either using different solvent, or varying treatment conditions such drying atmosphere, speed, annealing time, etc. All these techniques have been heavily investigated, and the best efficiency performance has been pushed to $5 \%$. Another way we suggest is to focus on the P3HT and PCBM molecules, especially P3HT. As its long chain is crucial in the charge transport process, we could chemically increase the chain length, to ensure the formation of the network in the active layer for charge carrier to transport. As to the decrease of contact resistance, the current trend is to add another layer $(\mathrm{LiF})$ under the $\mathrm{Al}$ contact to enhance the charge carrier collection. Further research could be conducted on the effect of adding additional layer on contact resistance values and optimizing post electrode deposition treatments to further reduce contact resistance.

One may think that reducing the 10 to $20 \Omega \mathrm{cm}^{2}$ series resistance level to $1 \Omega \mathrm{cm}^{2}$ is enough, as further reduction of the resistance provides very little efficiency increase. However, the 10 to $20 \Omega \mathrm{cm}^{2}$ series resistance level is the series resistance for device with about $80 \mathrm{~nm}$ to $100 \mathrm{~nm}$ thick active layer. The efficiency drops rapidly for devices with an active layer thicker than $100 \mathrm{~nm}$. This is due to the rapid increase of resistance after certain thickness. With thicker device, more photons will be absorbed, which ideally will lead to an increase in efficiency. However, the efficiency turns out to be decreasing. The explanation is that the increasing recombination rate, causes 
most of the charge carriers to end up in recombination instead of being collected by the electrodes. The next step of resistance reduction should be focused on this recombination issue. Doubling of the photocurrent density without the increase of resistance will directly double the efficiency. Basically there are two ways to solve this problem. One is to reduce the distance by inserting the electrode into the active layer, collect the charges before their recombination. The other way is to directly increase the diffusion length of the charge carriers to increase either its life time or increase its mobility. The first method can be implemented but it might also increase the complexity of fabrication process. The second method is a more direct way to solve the problem. 


\section{Chapter 3}

\section{Origin of $V_{O C}$}

\subsection{Statement of the Problem}

Although factors influencing $V_{O C}$ are still not fully understood, it is generally believed that the energy level offset between the HOMO of the donor and the LUMO of the acceptor $\left(E_{H O M O}^{D}-E_{L U M O}^{A}\right)$ minus the exciton binding energy $\left(E_{e x}\right)$ directly determines the value of $V_{O C}[28$. Studies on different donor/acceptor systems have been reported 28, 49, 50]. In 2006, Scharber et al. [28] studied 26 different organic solar cells (different donor materials and PCBM) and suggested that $V_{O C}$ should be linearly related to $\left(E_{H O M O}^{D}-E_{L U M O}^{A}\right)$ and an offset for bulk heterojunction devices. Rand et al. 49 investigated different small-molecular donor/acceptor systems and also obtained a similar relationship without an offset. All above could be summarized in the following equation:

$$
q V_{O C}=E_{H O M O}^{D}-E_{L U M O}^{A}-E_{e x}
$$

Barry et al. 50 proposed a modified explanation of almost the same equation 
Equation, claiming that it would only determine the maximum $V_{O C}$.

$$
q V_{O C}^{M a x}=E_{H O M O}^{D}-E_{L U M O}^{A}-E_{e x}
$$

In 2008, Potscavage et al. [51] further modified the relationship by studying the $V_{O C}$ of multilayer heterojunction organic solar cells.

$$
q V_{O C}=\frac{n}{n^{\prime}}\left(E_{H O M O}^{D}-E_{L U M O}^{A}\right)-n k T \ln \left(\frac{J_{00}}{J_{S C}}\right)
$$

Note that the second term on the right hand side of Equation 3.3 is based on the values of the reverse saturation current density $\left(J_{00}\right) . n$ is the ideal factor. $n^{\prime}$ is the ideal factor take into consideration of the effects such as vacuum level misalignments at the heterojunction caused by energy level bending and interface dipoles and the formation of charge-transfer states. The $\left(E_{H O M O}^{D}-E_{L U O M O}^{D}\right)$ term is renormalized by ideality factor $n^{\prime} . k$ is Boltzmann constant, $T$ is temperature.

However, comparison of measured $V_{O C}$ with theoretically calculated $V_{O C}$ based on the $\left(E_{H O M O}^{D}-E_{L U M O}^{A}\right)$ can not explain the complexity of $V_{O C}$. Many other factors, such as the film thickness, illumination intensity and temperature dependance can not be explained by these empirical formulas. Hence, further research work is required to understand the mechanism which drives the $V_{O C}$ of organic solar cell devices.

To study the origin of $V_{O C}$ of $\mathrm{P} 3 \mathrm{HT} / \mathrm{PCBM}$ solar cells, a study of the HOMO and LUMO levels and exciton binding energy of P3HT and PCBM at different temperatures were conducted to better examine the empirical equations. Ultraviolet Photoelectron Spectroscopy(UPS) was used to measure the HOMO levels of P3HT and PCBM in the temperature range from $25{ }^{\circ} \mathrm{C}$ to $145^{\circ} \mathrm{C}$. The UPS measured HOMO and LUMO levels and the measured $V_{O C}[52]$ were compared. The exciton 
binding energy was also measured to further examine the reported empirical formulas. Results have been published in IEEE Journal of Photovoltaics [53].

\section{$3.2 \quad$ Experiments}

The samples for UPS measurements were prepared by following steps: P3HT, PCBM and their blend solutions were spin-coated on a heavily arsenic doped $\left(1.06 \times 10^{19}\right.$ $/ \mathrm{cm}^{3}$ ) n-type Si substrate. These substrates were cut into $15 \times 15 \mathrm{~mm}^{2}$ and cleaned using Radio Corporation of America (RCA) cleaning procedure. P3HT, PCBM and their blend were dissolved in chlorobenzene 24 hours before the fabrication process. The solution concentrations were all 2 wt. $\%$, and were spin-coated on the RCA cleaned wafers at $900 \mathrm{rpm}$ for 1 minute. Then the samples were baked in a vacuum oven at $60{ }^{\circ} \mathrm{C}$ for 30 minutes. Finally, the samples were annealed at $130{ }^{\circ} \mathrm{C}$ for 2 minutes in air.

UPS measurements were then carried out in a vacuum chamber after the samples were exposed to ambient conditions for at least two days during shipping. 11 UPS measurements were performed in the dark on a Kratos AXIS-165 multi-technique electron spectrometer system with a base pressure of $5 \times 10^{-10}$ Torr. UPS data were collected with a He lamp source which produced a resonance line He I $(21.21 \mathrm{eV})$ by cold cathode capillary discharge. The spectra were acquired using hybrid lens that focused the ejected electrons into the Kratos spectrometer. A bias of - $20 \mathrm{~V}$ was applied to the sample to shift the spectra out of the nonlinear region of the analyzer (0 - $10 \mathrm{eV}$ kinetic energy). The energy resolution was determined at the Fermi edge of a clean Ag foil to be better than $150 \mathrm{meV}$.

\footnotetext{
${ }^{1}$ A collaboration was established with Professor Louis Scudiero's group of Washington State University
} 


\subsection{Data Analysis}

\subsubsection{Capacitance Measurements for Exciton Binding Ener- gy Calculation}

The capacitance of OSCs was measured to calculate the permittivity for the investigation of the origin of $V_{O C}$. The capacitance of OSCs were measured by HP 4275A Digital LCR Meter.

Figure 3.1 is the measured capacitance of P3HT/PCBM solar cell at different bias voltages.

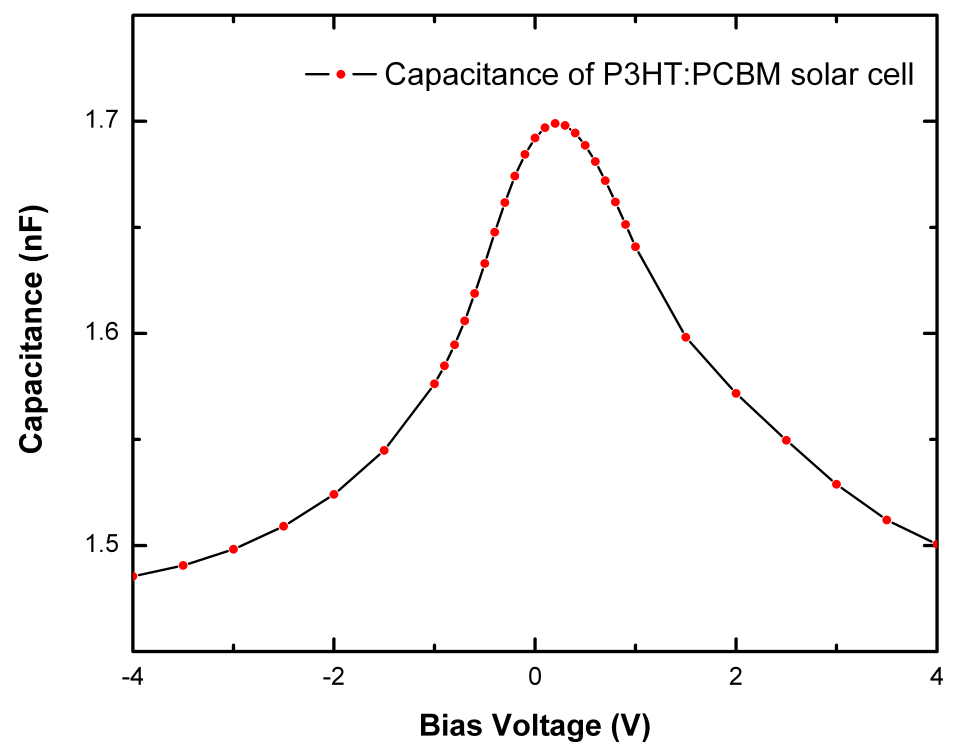

Figure 3.1: A typical C-V characteristic curve of P3HT/PCBM BHJ solar cell

The trend of the capacitance could be explained by introducing the schottky diode model as shown in Fig 3.2 .

The depletion capacitance $\left(C_{d}\right)$ follows the relation as Equation 3.4 shows. 


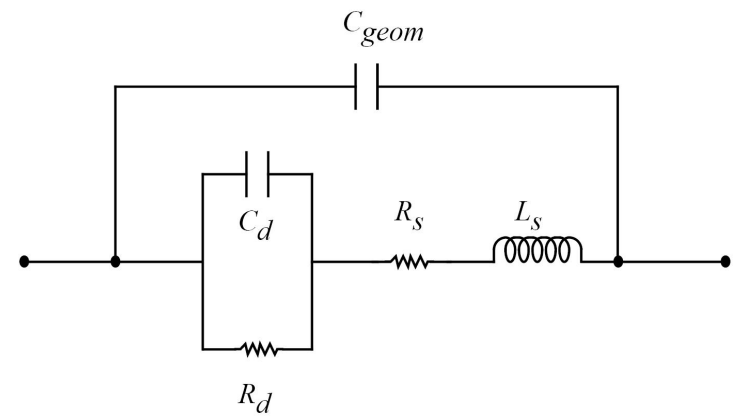

Figure 3.2: Equivalent circuit model of a schottky junction

$$
C_{d}=A\left[\frac{e \varepsilon_{0} \varepsilon_{r} N_{d}}{2\left(V-V_{b i}\right)}\right]^{\frac{1}{2}}
$$

$C_{d}$ is the depletion capacitance which is caused by the depletion region. $R_{d}$ is the diode resistance. $R_{S}$ and $L_{S}$ are series resistor and inductor of the device. $C_{\text {geom }}$ is the geometry capacitance determined by the structure of the device such as the area of contact. Note that $N_{d}$ is the doping concentration and $V_{b i}$ is the built-in voltage.

At high reverse bias, $\mathrm{V}<V_{b i}$, the organic layer becomes fully depleted, and $C_{d}$ decreases dramatically. However, the total capacitance will not drop to 0 because the capacitance levels off to the geometric value $C_{\text {geom. }}$. The $C_{\text {geom }}$ could be used to calculate the permittivity. At potential slightly negative to the built-in voltage, the $\mathrm{C}-\mathrm{V}$ characteristic shows an increasing trend as shown in Equation 3.4, following the schottky diode behavior. The capacitance peak position reveals the $V_{b i}$. At $\mathrm{V}$ $=V_{b i}$ (flat-band conditions) the depletion layer adjacent to the organic/Al contact disappears and the neutral region extends along the whole bulk. The Schottky barrier vanishes at $\mathrm{V}>V_{b i}$, the device capacitance keeps deceasing as electrons are injected into the LUMO of PCBM. It is then expected that the device capacitance is governed by a chemical capacitance due to the excess minority carriers [32,54,55].

In order to calculate the permittivity of P3HT for binding energy calculation, the 
geometric value $C_{\text {geom }}$ is collected.

$$
C_{\text {geom }}=\frac{\varepsilon_{P 3 H T} \cdot \varepsilon_{o} \cdot S}{d}
$$

With the area of the device, S, and the thickness of the device, d, the permittivity can be calculated.

\subsubsection{HOMO LUMO levels and Exciton Binding Energy}

To calculated the $V_{O C}$ from Equation 3.1. HOMO level of the donor (ionization potential of P3HT) and LUMO level of acceptor (electron affinity of PCBM) are required. The HOMO levels of both materials were obtained via UPS measurements as a function of temperature ranging from $25^{\circ} \mathrm{C}$ to $145^{\circ} \mathrm{C}$. The LUMO levels of PCBM are then obtained by subtracting the band gap energy from the HOMO levels. The values of HOMO of P3HT and LUMO of PCBM are shown in Figure 3.3.

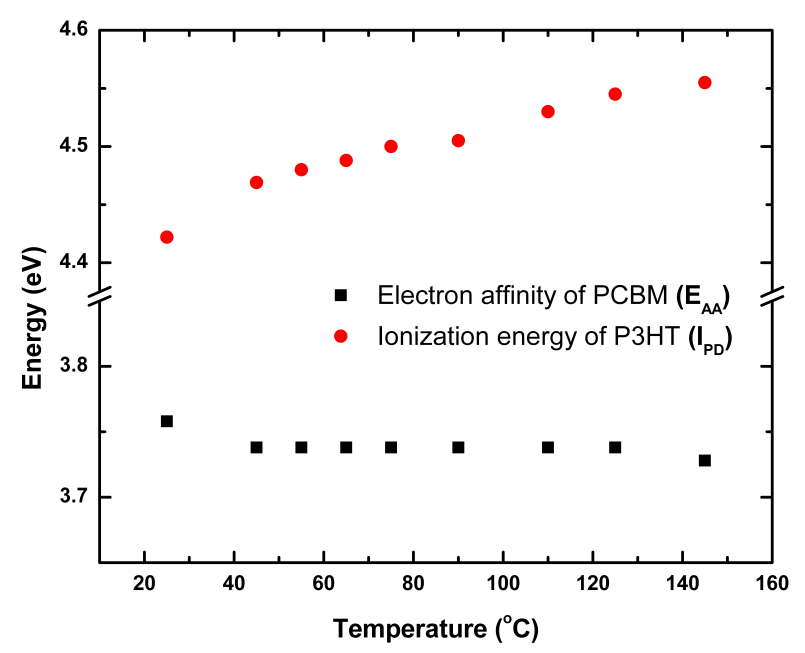

Figure 3.3: Ionization energy of P3HT $\left(I_{P D}\right)$ and electron affinity of $\mathrm{PCBM}\left(E_{A A}\right)$ as a function of temperature ranging from $25^{\circ} \mathrm{C}$ to $145^{\circ} \mathrm{C}$. 
The exciton binding energy value we used for the $V_{O C}$ calculation can also make a difference for the $V_{O C}$ comparison. For P3HT/PCBM system, it is a common practice [28, 56, 57 to set the the exciton binding energy as $0.3 \mathrm{eV}$. The $V_{O C}$ equals ionization potential $\left(I_{P D}\right)$ - electron affinity $\left(E_{A A}\right)-0.3 \mathrm{eV}$. However, it is very likely that the exciton binding energy is also temperature dependent. The exciton binding energy origins from the Coulomb force between the electron and hole $E_{e x}=e^{2} / 4 \pi \varepsilon_{0} \varepsilon_{r} d$ with e, the elementary charge, $\varepsilon_{0}$, the vacuum permittivity, $\varepsilon_{r}$, the dielectric constant of the organic material, and d, the initial distance between the electron and the hole, $\mathrm{d}$ was set to $2 \mathrm{~nm}$ in this calculation. With specific dielectric constant and distance selected, the Coulomb interaction energy can be calculated, and W. J. Grzegorczyk et al. reported values between 0.2 to $0.4 \mathrm{eV}$ [58]. 

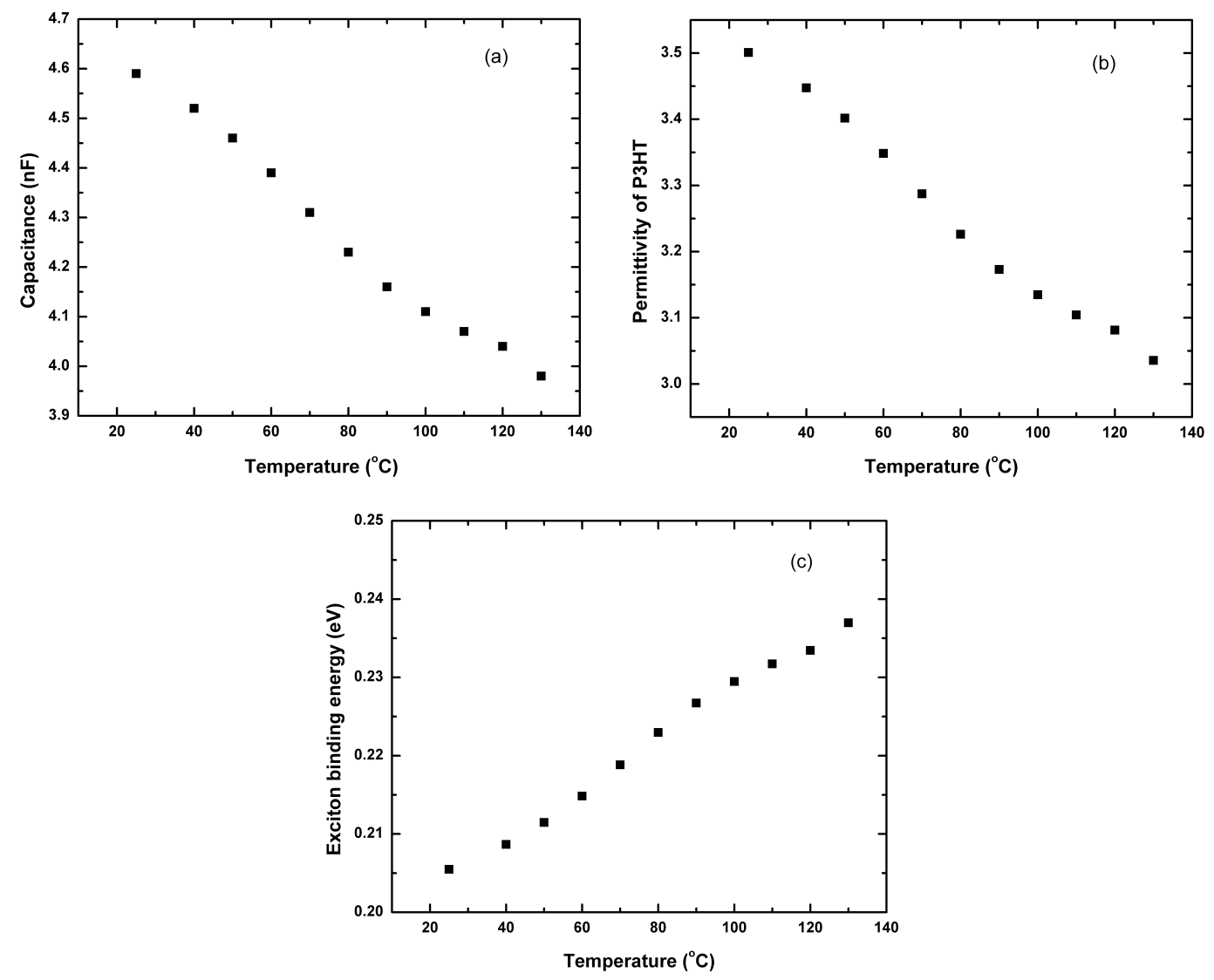

Figure 3.4: (a)The capacitance of P3HT in the temperature ranging from $25^{\circ} \mathrm{C}$ to $145^{\circ} \mathrm{C}$. (b) The permittivity of P3HT from $25^{\circ} \mathrm{C}$ to $145^{\circ} \mathrm{C}$. (c)Calculated exciton binding energy with the measured permittivity of P3HT.

The permittivity was then obtained by measuring the capacitance of pure P3HT device. (P3HT was spincoated on ITO coated glass and then Al was deposited to create a parallel capacitor). The capacitance was measured from $25^{\circ} \mathrm{C}$ and $125^{\circ} \mathrm{C}$, as shown in Figure 3.4(a). As the capacitance of a parallel capacitor is given by $C=\varepsilon_{0} \varepsilon_{r} A / l$, with $A$, the area of the parallel capacitor and $l$, the distance between the two plates $\left(A=0.12 \mathrm{~cm}^{2}\right.$ and $\left.l=81 \mathrm{~nm}\right)$, the permittivity of the dielectric can be calculated as shown in Figure 3.4(b). The exciton binding energy was then calculated as shown in Figure 3.4(c). Note that the measured permittivity is a bulk value at the thickness of around $100 \mathrm{~nm}$ and may be different at a separation distance of $2 \mathrm{~nm}$ 
between the electron and the hole.

\subsection{Discussion}

The $V_{O C}$ was then calculated using Equation 3.1 and compared with the experimentally measured $V_{O C}$ as shown in Figure 3.5 .

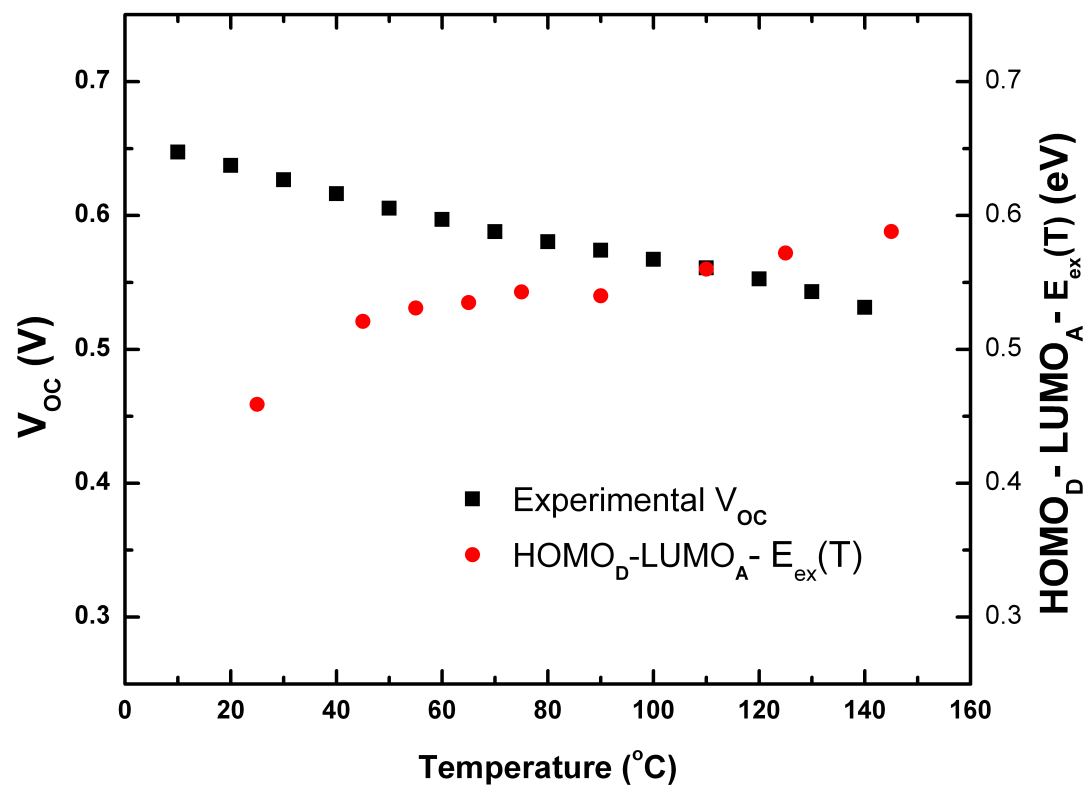

Figure 3.5: Comparison of calculated and experimental values of $V_{O C}$ as a function of temperature.

Figure 3.5 is the comparison of the measured value of $V_{O C}$ and the calculated value of $V_{O C}$ as a function of temperature. A clear linear relationship of the experimental value of $V_{O C}$ with temperature is observed. A monotonic decrease of $V_{O C}$ is noticed with increasing temperature for a total decrease of about $0.1 \mathrm{eV}$. The calculated $V_{O C}$ shows a nonlinear increasing trend. There are two major differences between the calculated and the experimentally measured $V_{O C}$. First, the calculated value is different from the value obtained experimentally. The two curves only overlap at 
one temperature point. Secondly, they show completely different trends. This drastic difference between calculated and measured values of $V_{O C}$ as a function of temperature indicates strongly that factors other than the offset between $\mathrm{HOMO}_{D}$ and $\mathrm{LUMO}_{A}$ affect the open circuit voltage of the device in the temperature range from $25^{\circ} \mathrm{C}$ to $145{ }^{\circ} \mathrm{C}$. Possible factors could be (1) the effect of electrode that is neglected here in this study and (2) the barrier of metal-organic interface that could play a key role in the origin of $V_{O C}$ and its temperature dependence. These factors are not considered in Equation 3.1. Modification of the equation is needed to better fit the calculated and experimentally measured values of $V_{O C}$.

By using Equation 3.3, Potscavage et al. [51] introduced the term $n k T \ln \left(J_{00} / J_{S C}\right)$ into the calculated $V_{O C}$ to take into consideration of the electrode factors and the interface factors. $J_{00}$ is the constant term indicating the reverse saturation current, and $J_{S C}$ is the short circuit current for the device. We calculated the $V_{O C}$ again and compared with the previous ones, as shown in figure 3.6.

As shown in figure 3.6, the two calculated $V_{O C}$ have little difference, indicating the new term $n k T \ln \left(J_{00} / J_{S C}\right)$ is not large enough to compensate the increasing trend of $E_{H O M O}^{D}-E_{L U M O}^{A}$. Several assumptions have been made when Potscavage et al. deduct Equation 3.3, which can not be accepted in the P3HT:PCBM solar cell case.

Potscavage et al. applied the one diode model showm in Equation 2.1 in their theory. At the $V=V_{O C}$ point, $I=0$, Equation 2.1 becomes:

$$
0=I_{L}-I_{0}\left[e^{\frac{q\left(V_{O C}-I R_{s}\right)}{n k T}}-1\right]-V_{O C} / R_{s h}
$$

Which can simply be written as:

$$
I_{0}\left[e^{\frac{q V_{O C}}{n k T}}-1\right]=I_{L}-V_{O C} / R_{s h}
$$




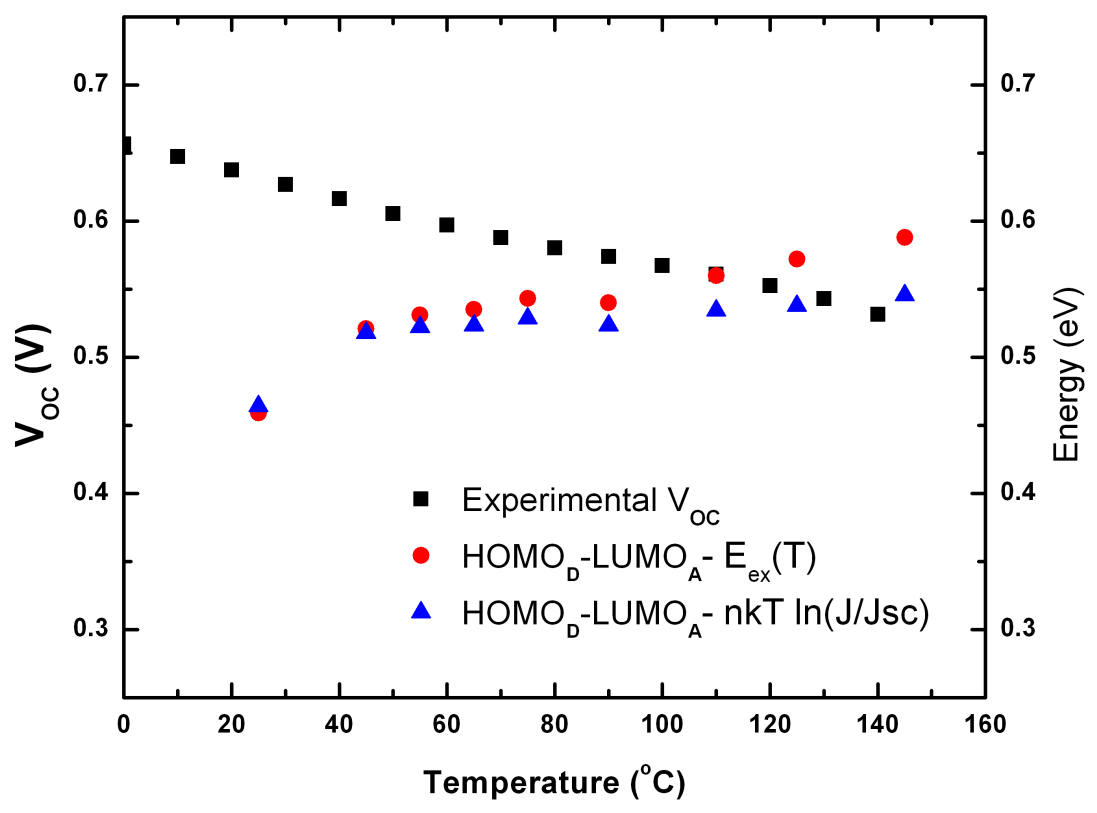

Figure 3.6: Comparison of calculated $V_{O C}$ with experimental measured values of $V_{O C}$ as a function of temperature.

From the data collected from the P3HT:CPBM solar cell produced in our labs, and also other work which reports the performance parameters of the P3HT:CPBM solar cell [48]. $I_{L}$ is in the range of $10 \mathrm{~mA} \cdot \mathrm{cm}^{-2}, R_{s h}$ is around $4000 \Omega \mathrm{cm}^{2}, V_{O C}$ $=0.65 \mathrm{~V}, V_{O C} / R_{s h}=0.175 \mathrm{~mA} \cdot \mathrm{cm}^{-2}$, much smaller than the value of $I_{L}$ as 10 $m A \cdot \mathrm{cm}^{-2}$, so the term $V_{O C} / R_{s h}$ can be neglected.

$$
\frac{q V_{O C}}{n k T}=\ln \left(I_{L} / I_{0}+1\right)
$$

As $I_{L} \approx I_{S C} \gg I_{0}$,

$$
q V_{O C}=n k T \ln \left(I_{S C} / I_{0}\right)
$$

The assumption Potscavage et al. made was that 


$$
I_{0}=I_{00} e^{\frac{E_{H O M O}^{D}-E_{L U M O}^{A}}{n k T}}
$$

They considered the value of effective bandgap, $\Delta \phi$ is equal to $E_{H O M O}^{D}-E_{L U M O}^{A}$. In a inorganic solar cell, Si solar cell for example, effective bandgap is the bandgap of the $\mathrm{Si}$; in an organic solar cell, it is fairly reasonable to think that $\left(E_{H O M O}^{D}-E_{L U M O}^{A}\right)$, which is offset between donor HOMO levels (similar to conduction band) and the acceptor LUMO levels (similar to valence band), would be the effective bandgap.

With this assumption, the equation becomes:

$$
q V_{O C}=\left(E_{H O M O}^{D}-E_{L U M O}^{A}\right)-n k T \ln \left(\frac{I_{00}}{I_{S C}}\right)
$$

With the ideal factor corrected, Equation 3.11 is the same with Equation 3.3 .

The key assumption is $I_{0}=I_{00} e^{\frac{E_{H O M O}^{D}-E_{L U M O}^{A}}{n k T}}$. Potscavage et al. proved this empirical relation of $\Delta \phi=E_{H O M O}^{D}-E_{L U M O}^{A}$ by fitting a pentacene $/ C_{60}$ solar cell's I-V characteristics. The relationship was correct for the material system, they then assumed all other donor acceptor systems would follow the same $\Delta \phi=E_{\text {HOMO }}^{D}$ $E_{L U M O}^{A}$ trend.

However, recent researches have shown that for different material systems, $\Delta \phi$ could be $\pm 0.1 \mathrm{eV}$ off with $E_{H O M O}^{D}-E_{L U M O}^{A}$ at room temperature, and the offset is even larger at higher temperature [59]. The temperature dependance offset between $\Delta \phi$ and $E_{H O M O}^{D}-E_{L U M O}^{A}$, named $\Delta \phi(T)^{\prime}$, should be added into Equation 3.3 .

$$
q V_{O C}=\frac{n}{n^{\prime}}\left[\left(E_{H O M O}^{D}-E_{L U M O}^{A}\right)-\Delta \phi(T)^{\prime}\right]-n k T \ln \left(\frac{J_{00}}{J_{S C}}\right)
$$

Our fitting results of P3HT:PCBM solar cell also proved that an extra $\Delta \phi(T)^{\prime}$ is needed to compensated the offset, as the calculated $V_{O C}$ from Equation 3.3 can not 
fit with the experimental data.

Several models have been introduced to explain why $E_{H O M O}^{D}-E_{L U M O}^{A}$ is not the effective bandgap in organic solar cells.

(i)Disorder induced tail state model. The tail states are density of states tail extended from HOMO and LUMO levels into the bandgap. Disorder induced tail states have been reported in several organic materials $[60-62]$. The value of the HOMO and LUMO level is often determined by means of photoemission yield spectroscopy, but the disorder induced tail states decline rapidly as the tail extends deeper into the bandgap, which is eventually beyond the range that the instrument can detect. However, the presence of the disorder induced tail states will trap charge carrier and decrease the potential difference. Therefore, the effective bandgap of organic materials is smaller than $\left(E_{H O M O}^{D}-E_{L U M O}^{A}\right)$.

(ii)Charge Transfer state, or CT state model [63 66]. CT state complexes are interfacial electron hole pairs residing at the donor acceptor interface. In a donor acceptor system, once an exciton reaches the donorCacceptor interface, it faces two kinds of energy states: the acceptor singlet state and the CT state. If the energy of the acceptor singlet state is lower than that of the CT state, energy transfer from donor to acceptor will occur. In this case, CT states will not affect $V_{O C}$. If the energy of CT state is lower, the exciton will populate the CT state, and the newly formed CT exciton will then either decay to the CT ground state or dissociate into polaron pairs. In this case, CT states will affect $V_{O C}$.

\subsection{Conclusion and Future work}

The $V_{O C}$ of organic solar cells is dependent on many factors. Temperature, illumination intensity, the work function of the electrode, and material microstructure are 
particularly important among these factors. We have used the $V_{O C}$ dependence on the temperature factor to study the relationship between $\left(E_{H O M O}^{D}-E_{L U M O}^{A}\right)$ and $V_{O C}$. The HOMO and LUMO levels of P3HT and PCBM have been measured via UPS. Different empirical equations were used to calculate $V_{O C}$ and the results were compared with the measured $V_{O C}$ of P3HT:PCBM organic solar cell devices. The calculated $V_{O C}$ does not match with the measured $V_{O C}$ due to $V_{O C}$ loss mechanism and empirical equations fail to take into consideration. In organic solar cells, $V_{O C}$ can be generally estimated to the scale of the difference between the HOMO level of the donor and the LUMO level of the acceptor with certain amount of loss (usually 0.3 $\mathrm{eV}$ in the P3HT:PCBM solar cell case). However, complex loss mechanisms due to disorder induced tail state and charge transfer state have to be take into consideration for exact computation of $V_{O C}$. In the disorder induced tail state model, the loss is mainly through electron tail states in the acceptor and hole tail states in the donor, whereas in the CT state model, the loss is directly through CT states at the donor acceptor interface. While both models can explain the $V_{O C}$ to some extent, further research work is needed to gain a deeper understanding of both models. 


\section{Chapter 4}

\section{Thermal Conductivity Study of Organic Solar Cell Materials}

\subsection{Background}

Organic polymers have received attention as protential thermoelectric materials very recently 67 69, base on the the fact that they are semiconducting and that they could exhibit relatively low thermal conductivities. Disordered polymeric chains often exhibit thermal conductivities an order of magnitude smaller than that of silica glass 69 [74. Thermal characteristics of polymeric thin films are very sensitive to the arrangement of the molecular chains. For example, well-aligned polymeric chains can exhibit exceptionally high thermal conductivities [75], in stark contrast with the disordered polymeric chains described above 69 74. In disordered polymeric films, thermal conductivities exhibit temperature-dependence that are typical of amorphous solids, and heat transfer is limited by a random walk of localized energy on the time and length scales of atomic vibrations and interatomic spacing, respectively [76 78]. Thermal annealing of common bulk heterojunction blends can lead to the 
alignment of polymer chains and the formation of large crystallites 79,80$]$, further demonstrating a need for the adequate thermal characterization of these materials. The issue of molecular arrangement is of particular interest in the context of the present material systems (e.g., P3HT:PCBM blends) as thermal annealing of common bulk heterojunction blends can lead to the alignment of polymer chains and the formation of large crystallites $[79,80$.

\section{$4.2 \quad$ Experiments}

1

We measured the thermal conductivities of PCBM, P3HT, P3HT:PCBM blend, and PEDOT:PSS thin films as a function of temperature from 319 to 396 K. Experimental details have been described in [81, 82].

The organic thin film samples were prepared according to the following procedure: indium tin oxide (ITO) coated glass substrates (provided by Delta Technologies) were first cleaned with acetone and isopropyl alcohol and subsequently dried in air. Highlyconductive PEDOT:PSS provided by H.C. Stark was then spin-casted (4000 rpm) on these substrates from aqueous solution. The PEDOT:PSS films had an average thicknesses of $56 \mathrm{~nm}$, and were baked for 15 minutes at $110^{\circ} \mathrm{C}$ in air. Of these substrates, one was set aside to serve as the PEDOT:PSS reference sample, while the others received further processing. For the PCBM, P3HT, and blend films, P3HT and PCBM (provided by Sigma-Aldrich and Nano-C, respectively) were dissolved in chlorobenzene 24 hours before fabrication. The PCBM, P3HT, and blend solutions were $1 \mathrm{wt} \%$ and the blend solutions were composed of a variable ratio of $\mathrm{P} 3 \mathrm{HT}$ to

\footnotetext{
${ }^{1}$ For thermal conductivity measurements, a collaboration was established with Professor Patrick Hopkins's group of UVa, all thermal measurements were carried out by John Duda in Professor Hopkins's laboratory.
} 
PCBM (10:90, 45:55, or 90:10). The solutions were then spin-casted at various speeds on the PEDOT:PSS coated substrates, producing film thicknesses from 25 to $200 \mathrm{~nm}$. All but one series of P3HT:PCBM blend films were annealed in air at $130^{\circ} \mathrm{C}$ for 2 minutes. A nominally $80 \mathrm{~nm}$ thick $\mathrm{Al}$ film was then deposited on the films (including on the PEDOT:PSS reference sample) via electron beam evaporation.

The thermal conductivities of these films were measured by TDTR (Time-domain Thermo Reflectance), a non-contact, pump-probe optical thermometry technique 83 86. In short, TDTR is a pump-probe technique in which $100 \mathrm{fs}$ laser pulses emanate from a Spectra Physics Tsunami at an $80 \mathrm{MHz}$ repetition rate. The time delay of the probe pulse reaches the sample relative to the pump pulse was achieved by way of a mechanical delay stage (for a maximum delay of $\approx 5.2 \mathrm{~ns}$ ). Our pump and probe spots are focused to $1 / e^{2}$ radii of 25 and $12 \mu m$ at the sample surface. At these sizes and at the $11.39 \mathrm{MHz}$ pump modulation frequency we are negligibly sensitive to any in-plane transport in the films, thus decreasing the uncertainty associated with determining the cross-plane thermal conductivity [87]. A total of six TDTR measurements were carried out on each film at ambient temperatures from 294 to 375 $\mathrm{K}$ in a cryostat with optical access that is kept under vacuum $(<1.0 \mathrm{mTorr})$. The maximum temperature was limited to $375 \mathrm{~K}$ to prevent the melting of or structural changes to the polymers $[79]$. In addition, the total incident laser power was limited to $\approx 20 \mathrm{~mW}$; still, due to the low thermal conductivity of thermal sink (glass base plate), the temperature rise due to the incident laser beams was $\approx 22 \mathrm{~K}[83$.

\subsection{Results and Discussion}

Thermal conductivities of the PEDOT:PSS, P3HT, and P3HT:PCBM blend films are shown in Figure 4.1. In addition, we plot the thermal conductivity of amorphous 
carbon from Ref. $88\left(\rho=0.9 \mathrm{~g} \mathrm{~cm}^{-3}\right)$, thin film PCBM from Ref. [82], and a previous room temperature measurement of P3HT from Ref. 89. The thermal conductivities of P3HT $\left(0.185 \pm 0.011 \mathrm{~W} \mathrm{~m}^{-1} \mathrm{~K}^{-1}\right)$ near room temperature are in good agreement with those previously reported (see Refs. 74, 89]). Also in Figure 4.1, we report data on PCBM films with different thicknesses and processing conditions than those reported in Ref. 82]. At this time, we do not understand the origin of the variation in thermal conductivities of the different PCBM films. However, we speculate that the different processing conditions and substrates can lead to different packing densities or inhomogeneities in the structure or composition in the spin-casted PCBM films. This could be reflected in the variations of heat capacities that we inferred from our TDTR data. Even still, PCBM films represent ultra-low thermal conductivity solids, as we discuss in detail in Ref. 82 .

Also shown in Figure 4.1 is that annealing P3HT:PCBM blend films can lead to an increase in thermal conductivity of approximately $40 \%$. This correlates with the evolution of P3HT:PCBM morphology during annealing as increased molecular mobility will lead to P3HT crystallite formation and PCBM aggregation 80, 90. However, we believe that any increase in thermal conductivity is due to alignment alone and not aggregation. 


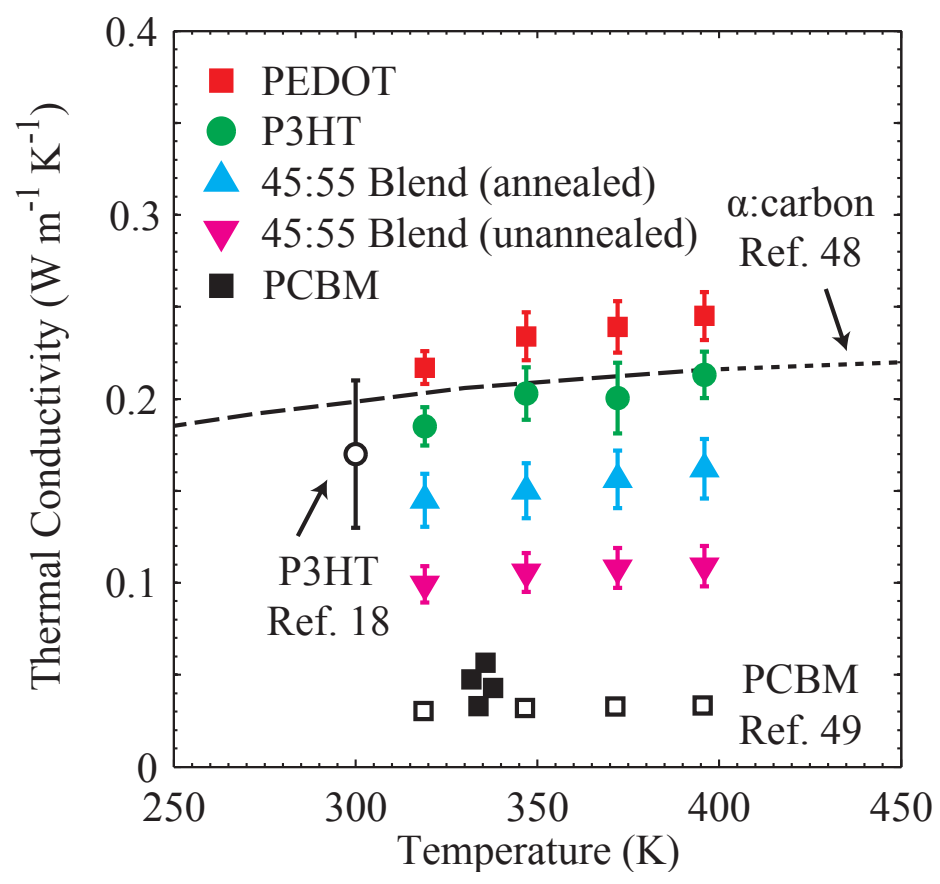

Figure 4.1: Thermal conductivities of the PEDOT:PSS, P3HT, PCBM, and P3HT:PCBM films, along with previously published thermal conductivities of amorphous carbon (dashed line), thin film PCBM (open squares), and P3HT (open circle).[81]

From the plot, it is clear that while thermal annealing can lead to increase in the thermal conductivity, this effect is variable and a large discrepancy is found among the thermal conductivities of 45:55 blends (which are horizontally offset in the figure for clarity). At present, we are unsure of the cause for this variability, though we hypothesize that our annealing procedure led to different degrees of polymer alignment within those films [90]. Also of interest is the fact that a rule of mixtures holds for the thermal conductivity of polymer-blend thin films, as opposed to the dramatic decrease in thermal conductivity observed in bulk and thin-film semiconductor alloys 91, 92. 


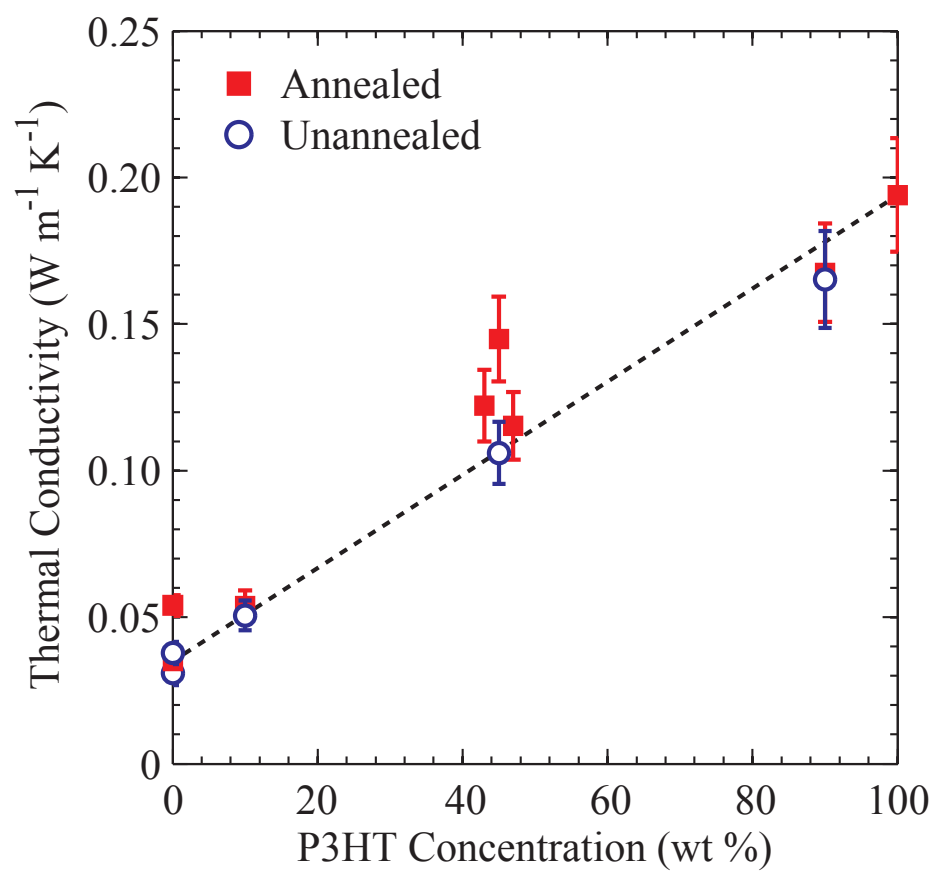

Figure 4.2: Thermal conductivities of the P3HT:PCBM blend films as a function of weight percent P3HT.[81]

Filled squares represent data taken from annealed samples and hollow circles from unannealed samples. The dashed line is a linear interpolation between the conductivities of pure PCBM and P3HT thin films fabricated in an identical fashion. The data suggest that a rule of mixtures applies, where thermal conductivity is a linear function of film composition. The three measurements taken on annealed 45:55 blends have been (horizontally) offset slightly for clarity

In agreement with the literature reporting on the structure of PCBM films processed via chlorobenzene solution [79,93], the observation of distinct rings in the diffraction pattern generated by electron beam diffraction (shown in Figure 4.3) confirmed the microcrystallinity of the films. As one might expect, the diffraction patterns also indicate that annealing lead to further crystallization. 

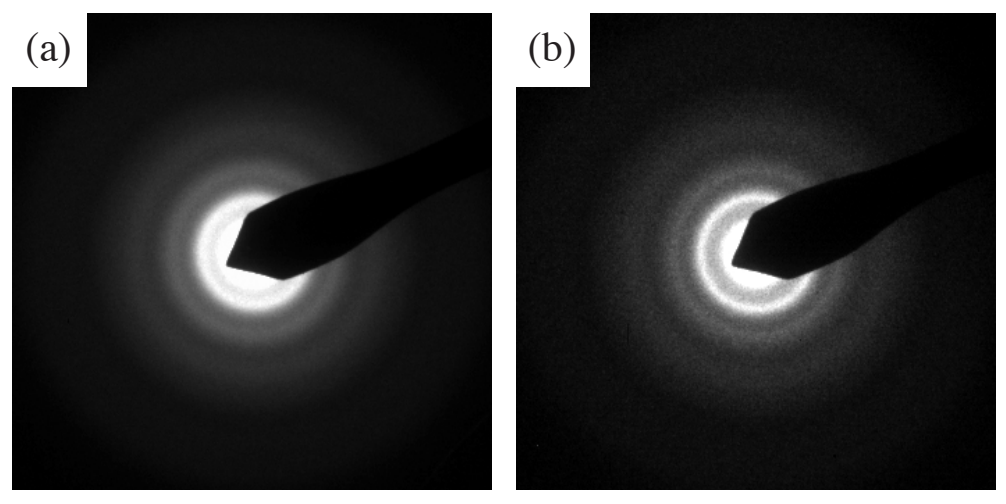

Figure 4.3: Electron diffraction patterns of (a) unannealed and (b) annealed PCBM films. Note the rings in diffraction pattern from the annealed sample are more distinct than they are in the unannealed sample, indicating an increase in crystallinity.[81]

Finally, the thermal conductivities of P3HT films near room temperature (319 K) are plotted as a function of film thickness in Figure 4.4. Conductivities of films 77 to $200 \mathrm{~nm}$ thick) range from $0.185 \pm 0.011$ to $0.213 \pm 0.013 \mathrm{~W} \mathrm{~m}^{-1} \mathrm{~K}^{-1}$. The relatively small changes in conductivity with film thickness, together with the nonmonotonic trends, suggest that the "thinness" of the films is not responsible for the low thermal conductivities (boundary effects would scale with thickness). This lack of size dependence is consistent with earlier observations of the thermal conductivities of $\mathrm{CuPc}[73$ and PCBM [82] thin films. Furthermore, this reaffirms our treatment of the polymer films as semi-infinite in our thermal model despite their relative thinness (the thermal penetration depth at our modulation frequency is roughly $60 \mathrm{~nm}$ in the P3HT films). The data is thus consistent with the picture that thermal transport in polymeric films is dominated by a random walk of vibrational energy. 


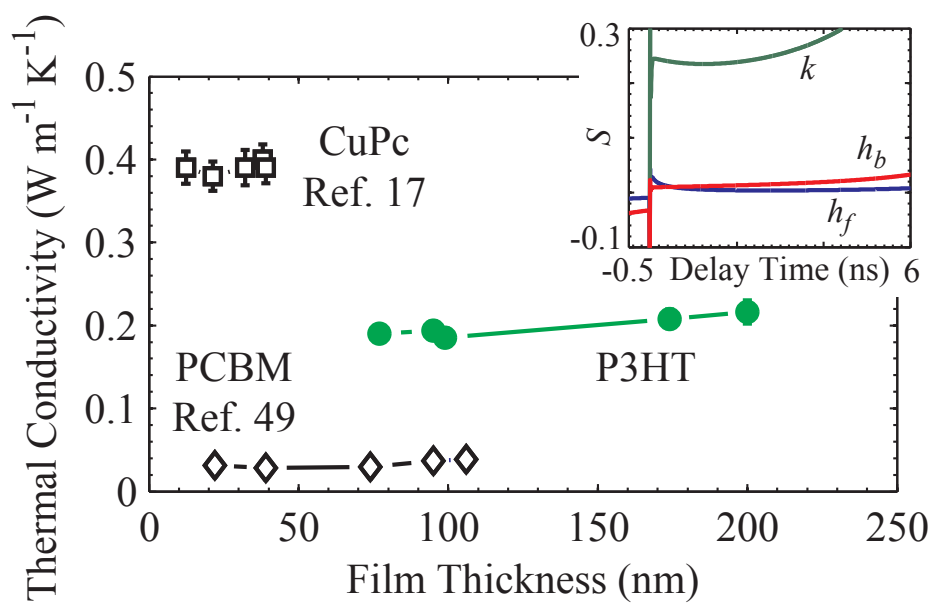

63

Figure 4.4: Thermal conductivities of P3HT (filled circles), CuPc (hollow squares) and PCBM (hollow diamonds) films as a function of film thickness.[81]

\subsection{Conclusions}

In the thermal conductivity of organic materials study, the thermal conductivities of PEDOT:PSS, PCBM, P3HT and P3HT:PCBM blend thin films were measured by time domain thermoreflectance. The thermal conductivities of these films are insensitive to changes in temperature from 319 to $396 \mathrm{~K}$. The thermal conductivities of blend films follow a rule of mixtures and thermal annealing of these films leads to an increase in thermal conductivity. The thermal conductivities of P3HT thin films exhibit no sign of size effects down to film thicknesses of $77 \mathrm{~nm}$. At this time, we do not understand the origin of the variation in thermal conductivities of the different PCBM films. However, we speculate that the different processing conditions and substrates can lead to different packing densities or inhomogeneities in the structure or composition in the spin-casted PCBM films. 


\section{Chapter 5}

\section{Conclusions}

This thesis is mainly about the investigation of the electrical properties of P3HT:PCBM organic solar cells: the conducting mechanism is studied via resistance measurements of the OSC devices and the origin of $V_{O C}$ is investigated through ultraviolet photoelectron spectroscopy (UPS).

In the conduction mechanism study, the investigation of the series resistance of the OSC devices have been completed. Contact resistance and bulk resistance have been extracted from series resistance measurements. Compared with the bulk resistance, the contact resistance is relatively small but still not negligible. The effect of thermal annealing was studied. Thermal annealing reduces the series resistance, especially for devices with an active layer thickness greater than $80 \mathrm{~nm}$. This is because the diffusion length of charge carriers in P3HT:PCBM solar cells is around $80 \mathrm{~nm}$. For devices thicker than $80 \mathrm{~nm}$, recombination can be expected to increase rapidly, which will lead to a rapid increase of series resistance. Thermal annealing of the devices reduces both contact and bulk resistance: the contact resistance dropped by a factor of 2 , while the bulk resistance dropped by a factor of 8 . This factor depends on the active layer thickness. Further research work is suggested on the effect of adding 
another layer on contact resistance values and optimizing post electrode deposition treatments to further reduce contact resistance.

In the origin of $V_{O C}$ study, the HOMO and LUMO levels of P3HT and PCBM have been measured, and then the calculated $V_{O C}$ and the measured $V_{O C}$ were compared. The $V_{O C}$ of P3HT/PCBM solar cell steadily decreased linearly when increasing the temperature between $25{ }^{\circ} \mathrm{C}$ and $145^{\circ} \mathrm{C}$, while the $V_{O C}$ calculated by using the offset between $H O M O_{D}$ and $L U M O_{A}$ showed a non-linear increasing trend. Other possible factors such as the effect of electrode and the barrier of metal-organic interface could play a key role in the origin of $V_{O C}$ and its temperature dependence. Further research work on the effect of illumination on the energy levels and electrode-organic interface is described.

The results of thermal conductivity of organic materials and investigation of femtosecond laser interaction with fused silica are presented. In the thermal conductivity of organic materials study, the thermal conductivities of PEDOT:PSS, PCBM, P3HT and P3HT:PCBM blend thin films were measured by time domain thermoreflectance. From 319 to $396 \mathrm{~K}$, the thermal conductivities of these films were found to be insensitive to changes in temperature. The thermal conductivities of blend films follow a rule of mixtures and thermal annealing of these films leads to a variable increase in thermal conductivity, which we attribute to changes in morphology that results from the annealing. Lastly, the thermal conductivities of P3HT thin films exhibit no sign of thickness effects down to film thicknesses of $77 \mathrm{~nm}$. The room-temperature thermal conductivities of PCBM thin films are the lowest reported of any fully dense solid. 


\section{Chapter 6}

\section{Bibliography}

[1] R. Bird, R. Hulstrom, and L. Lewis, "Terrestrial solar spectral data sets," Solar Energy, vol. 30, no. 6, pp. $563-573,1983$.

[2] D. G. Collins, W. G. Blättner, M. B. Wells, and H. G. Horak, "Backward monte carlo calculations of the polarization characteristics of the radiation emerging from spherical-shell atmospheres," Appl. Opt., vol. 11, no. 11, pp. 2684-2696, 1972.

[3] K. A. Tsokos, Physics for the IB Diploma. Cambridge University Press, 2008.

[4] D. M. Chapin, "Solar energy converting apparatus," 1957, US Patent 2,780,765.

[5] J. Perlin, The Silicon Solar Cell Turns 50. National Renewable Energy Laboratory, 2010.

[6] U. D. of Energy, Annual Energy Outlook 2013, April 2013.

[7] W. Shockley and H. Queisser, "Detailed balance limit of efficiency of p-n junction solar cells," Journal of Applied Physics, vol. 32, no. 3, pp. 510-519, 1961. 
[8] U. D. of Energy, 2010 solar technologies market report, November 2011.

[9] F. Krebs, J. Fyenbo, and M. Jorgensen, "Product integration of compact roll-to-roll processed polymer solar cell modules: methods and manufacture using flexographic printing, slot-die coating and rotary screen printing," $J$. Mater. Chem., vol. 20, pp. 8994-9001, 2010.

[10] W. Potscavage, A. Sharma, and B. Kippelen, "Critical interfaces in organic solar cells and their influence on the open-circuit voltage," Accounts of Chemical Research, vol. 42, no. 11, pp. 1758-1767, 2009.

[11] M. A. Green, K. Emery, Y. Hishikawa, W. Warta, and E. D. Dunlop, "Solar cell efficiency tables (version 42)," Progress in Photovoltaics: Research and Applications, vol. 21, no. 5, pp. 827-837, 2013.

[12] B. Kippelen and J. Bredas, "Organic photovoltaics," Energy Environ. Sci., vol. 2, pp. 251-261, 2009.

[13] H.Hoppe and N. S. Sariciftci, "Organic solar cells: An overview," Journal of Materials Research, vol. 19, pp. 1924-1945, 2004.

[14] T. Kietzke, "Recent advances in organic solar cells," Advances in OptoElectronics, vol. 2007, pp. 40 285-1-40 285-15, 2007.

[15] C. Deibel and V. Dyakonov, "Polymer-fullerene bulk heterojunction solar cells," Rep. Prog. Phys, vol. 73, p. 096401, 2010.

[16] G. Yu, J. Gao, J. C. Hummelen, F. Wudl, and A. J. Heeger, "Polymer photovoltaic cells: Enhanced efficiencies via a network of internal donor-acceptor heterojunctions," Science, vol. 270, no. 5243, pp. 1789-1791, 1995. 
[17] C. J. Brabec, S. E. Shaheen, C. Winder, N. S. Sariciftci, and P. Denk, "Effect of $\mathrm{LiF} /$ metal electrodes on the performance of plastic solar cells," Applied Physics Letters, vol. 80, no. 7, pp. 1288-1290, 2002.

[18] P. W. M. Blom, M. J. M. de Jong, and S. Breedijk, "Temperature dependent electron-hole recombination in polymer light-emitting diodes," Applied Physics Letters, vol. 71, no. 7, pp. 930-932, 1997.

[19] G. Dennler, M. C. Scharber, and C. Brabec, "Polymer-fullerene bulkheterojunction solar cells," Advanced Materials, vol. 21, no. 13, pp. 1323-1338, 2009.

[20] G. Namkoong, P. Boland, K. Lee, and J. Dean, "Design of organic tandem solar cells using PCPDTBT:PC ${ }_{61} \mathrm{BM}$ and P3HT:PC ${ }_{71} \mathrm{BM}$," Journal of Applied Physics, vol. 107, no. 12, p. 124515, 2010.

[21] S. H. Park, A. Roy, S. Beaupre, S. Cho, N. Coates, J. Moon, D. Moses, M. Leclerc, K. Lee, and A. Heeger, "Bulk heterojunction solar cells with internal quantum efficiency approaching 100\%," Nature Photonics, vol. 3, pp. 297 - 302, 2009.

[22] M. Campoy-Quiles, T. Ferenczi, T. Agostinelli, P. Etchegoin, Y. Kim, T. Anthopou, P. Stavrinou, D. Bradley, and J. Nelson, "Morphology evolution via self organizationand lateral and vertical diffusion in polymerfullerene solar cell blends," Nature Materials, vol. 7, pp. 158-164, 2008.

[23] H. Tompkins and E. Irene, Handbook of Ellipsometry. William Andrew Publishing, 2008.

[24] M. Fried, P. Petrik, T. Lohner, N. Khnh, O. Polgr, and J. Gyulai, "Dose-dependence of ion implantation-caused damage in silicon measured by 
ellipsometry and backscattering spectrometry," Thin Solid Films, vol. 455C456, no. 0 , pp. $404-409,2004$.

[25] J. Kim, S. Kim, H.-H. Lee, K. Lee, W. Ma, X. Gong, and A. Heeger, "New architecture for high-efficiency polymer photovoltaic cells using solution-based titanium oxide as an optical spacer," Advanced Materials, vol. 18, no. 5, pp. $572-576,2006$.

[26] V. Coropceanu, J. Cornil, D. da Silva Filho, Y. Olivier, R. Silbey, and J.-L. Brodas, "Charge transport in organic semiconductors," Chemical Reviews, vol. 107, no. 4, pp. 926-952, 2007.

[27] L. Hung, C. Tang, and M. Mason, "Enhanced electron injection in organic electroluminescence devices using an Al/LiF electrode," Applied Physics Letters, vol. 70, no. 2, pp. 152-154, 1997.

[28] M. Scharber, D. Mhlbacher, M. Koppe, P. Denk, C. Waldauf, A. Heeger, and C. Brabec, "Design rules for donors in bulk-heterojunction solar cells:towards $10 \%$ energy-conversion efficiency," Advanced Materials, vol. 18, no. 6, pp. 789-794, 2006.

[29] R. Kepler, "Charge carrier production and mobility in anthracene crystals," Phys. Rev., vol. 119, pp. 1226-1229, 1960.

[30] G. Horowitz, R. Hajlaoui, H. Bouchriha, R. Bourguiga, and M. Hajlaoui, "The concept of threshold voltage in organic field-effect transistors," Advanced Materials, vol. 10, no. 12, pp. 923-927, 1998.

[31] M. Pope and C. Swenberg, Electronic Processes in Organic Crystals and Polymers. Oxford University Press, New York, 2009. 
[32] S. Sze, Physics of Semiconductor Devices. Wiley-Interscience, 1981.

[33] A. Goetzberger, J. Knobloch, and B. Voss, Crystalline Silicon Solar Cells. Wiley, 1998.

[34] J. Xue, S. Uchida, B. Rand, and S. Forrest, "4.2\% efficient organic photovoltaic cells with low series resistances," Applied Physics Letters, vol. 84, no. 16, pp. 3013-3015, 2004.

[35] J. Zhao, A. Wang, P. Altermatt, S. Wenham, and M. Green, " $24 \%$ efficient silicon solar cells," vol. 2, pp. $1477-1480,1994$.

[36] G. Li, V. Shrotriya, Y. Yao, and Y. Yang, "Investigation of annealing effects and film thickness dependence of polymer solar cells based on poly(3-hexylthiophene)," Journal of Applied Physics, vol. 98, no. 4, p. 043704, 2005.

[37] A. E. Rakhshani, "Heterojunction properties of electrodeposited CdTe/CdS solar cells," Journal of Applied Physics, vol. 90, no. 8, pp. 4265-4271, 2001.

[38] G. Reeves and H. Harrison, "Obtaining the specific contact resistance from transmission line model measurements," Electron Device Letters, IEEE, vol. 3, no. 5, pp. $111-113,1982$.

[39] H. Berger, "Models for contacts to planar devices," Solid-State Electronics, vol. 15 , no. 2 , pp. $145-158,1972$.

[40] T. Aernouts, W. Geens, J. Poortmans, P. Heremans, S. Borghs, and R. Mertens, "Extraction of bulk and contact components of the series resistance in organic bulk donor-acceptor-heterojunctions," Thin Solid Films, vol. 404, no. 0, pp. 297 - 301, 2002. 
[41] Y. Kim, S. Choulis, J.Nelson, D. Bradley, S. Cook, and J. Durrant, "Device annealing effect in organic solar cells with blends of regioregular poly(3-hexylthiophene) and soluble fullerene," Applied Physics Letters, vol. 86, no. 6, p. 063502, 2005.

[42] M.Al-Ibrahim, O.Ambacher, S.Sensfuss, and G. Gobsch, "Effects of solvent and annealing on the improved performance of solar cells based on poly(3hexylthiophene): Fullerene," Applied Physics Letters, vol. 86, no. 20, p. 201120, 2005.

[43] Y. Shen, K. Li, N. Majumdar, J. C. Campbell, and M. C. Gupta, "Bulk and contact resistance in P3HT:PCBM heterojunction solar cells," Solar Energy Materials and Solar Cells, vol. 95, no. 8, pp. 2314 - 2317, 2011.

[44] Y. Shen and M. C. Gupta, "Investigation of electrical characteristics of P3HT:PCBM organic solar cells," in Photovoltaic Specialists Conference (PVSC), 2012 38th IEEE, 2012, pp. 002770-002 774.

[45] M. Lampert and P. Mark, Current Injection in Solids. New York, 1970.

[46] P.Kumar, S. Jain, V. Kumar, S. Chand, and R. Tandon, "A model for the J-V characteristics of P3HT:PCBM solar cells," Journal of Applied Physics, vol. 105, no. 10, p. 104507, 2009.

[47] E. J. McGinness, "Mobility gaps: A mechanism for band gaps in melanins," Science, vol. 177, no. 4052, pp. 896-897, 1972.

[48] J. Servaites, S. Yeganeh, T. Marks, and M. Ratner, "Efficiency enhancement in organic photovoltaic cells: Consequences of optimizing series resistance," Advanced Functional Materials, vol. 20, no. 1, pp. 97-104, 2010. 
[49] M. Brumbach, D. Placencia, and N. Armstrong, "Titanyl phthalocyanine/ $/ c_{60}$ heterojunctions: Band-edge offsets and photovoltaic device performance," The Journal of Physical Chemistry C, vol. 112, no. 8, pp. 3142-3151, 2008.

[50] B. Rand, D. Burk, and S. Forrest, "Offset energies at organic semiconductor heterojunctions and their influence on the open-circuit voltage of thin-film solar cells," Phys. Rev. B, vol. 75, p. 115327, 2007.

[51] W. Potscavage, S. Yoo, and B. Kippelen, "Origin of the open-circuit voltage in multilayer heterojunction organic solar cells," Applied Physics Letters, vol. 93, no. 19, p. 193308, 2008.

[52] W. Bagienski and M. C. Gupta, "Temperature dependence of polymer/fullerene organic solar cells," Solar Energy Materials and Solar Cells, vol. 95, no. 3, pp. $933-941,2011$.

[53] Y. Shen, L. Scudiero, and M. C. Gupta, "Temperature dependence of open-circuit voltage and ups study for P3HT:PCBM organic solar cells," IEEE Journal of Photovoltaics, vol. 2, no. 4, pp. 512-518, 2012.

[54] I. Mora-Sero, Y. Luo, G.Garcia-Belmonte, J. Bisquert, D.Muoz, C.Voz, J. Puigdollers, and R. Alcubilla, "Recombination rates in heterojunction silicon solar cells analyzed by impedance spectroscopy at forward bias and under illumination," Solar Energy Materials and Solar Cells, vol. 92, no. 4, pp. 505 $509,2008$.

[55] J. Bisquert, D. Cahen, G. Hodes, S. Ruehle, and A. Zaban, "Physical chemical principles of photovoltaic conversion with nanoparticulate, mesoporous dye-sensitized solar cells," ChemInform, vol. 35, no. 36, pp. 8106-8118, 2004. 
[56] B. Rand, D. Burk, and S. Forrest, "Offset energies at organic semiconductor heterojunctions and their influence on the open-circuit voltage of thin-film solar cells," Phys. Rev. B, vol. 75, p. 115327, 2007.

[57] T. Yamanari, T.Taima, J. Sakai, and K. Saito, "Origin of the open-circuit voltage of organic thin-film solar cells based on conjugated polymers," Solar Energy Materials and Solar Cells, vol. 93, no. 67, pp. 759 - 761, 2009, 17th International Photovoltaic Science and Engineering Conference.

[58] W. Grzegorczyk, T. Savenije, T. Dykstra, J. Piris, J. Schins, and L. Siebbeles, "Temperature-Independent Charge Carrier Photogeneration in P3HT/PCBM Blends with Different Morphology," The Journal of Physical Chemistry C, vol. 114, no. 11, pp. 5182-5186, 2010.

[59] J. Widmer, M. Tietze, K. Leo, and M. Riede, "Open-circuit voltage and effective gap of organic solar cells," Advanced Functional Materials, doi = 10.1002/adfm.201301048, 2013.

[60] I. N. Hulea, H. B. Brom, A. J. Houtepen, D. Vanmaekelbergh, J. J. Kelly, and E. A. Meulenkamp, "Wide energy-window view on the density of states and hole mobility in poly(p-phenylene vinylene)," Phys. Rev. Lett., vol. 93, p. $166601,2004$.

[61] O. Tal, Y. Rosenwaks, Y. Preezant, N. Tessler, C. K. Chan, and A. Kahn, "Direct determination of the hole density of states in undoped and doped amorphous organic films with high lateral resolution," Phys. Rev. Lett., vol. 95, p. $256405,2005$. 
[62] T. Sueyoshi, H. Fukagawa, M. Ono, S. Kera, and N. Ueno, "Low-density band-gap states in pentacene thin films probed with ultrahigh-sensitivity ultraviolet photoelectron spectroscopy," Applied Physics Letters, vol. 95, no. 18, p. $183303,2009$.

[63] J. Benson-Smith, L. Goris, K. Vandewal, K. Haenen, J. Manca, D. Vanderzande, D. Bradley, and J. Nelson, "Formation of a Ground-State Charge-Transfer Complex in Polyfluorene//[6,6]-Phenyl-C61 Butyric Acid Methyl Ester (PCBM) Blend Films and Its Role in the Function of Polymer/PCBM Solar Cells," Advanced Functional Materials, vol. 17, no. 3, pp. 451-457, 2007.

[64] D. Veldman, S. Meskers, and R. Janssen, "The energy of charge-transfer states in electron donorcacceptor blends: Insight into the energy losses in organic solar cells," Advanced Functional Materials, vol. 19, no. 12, pp. 1939-1948, 2009.

[65] A. Maurano, R. Hamilton, C. Shuttle, A. Ballantyne, J. Nelson, B. ORegan, W. Zhang, I. McCulloch, H. Azimi, M. Morana, C. Brabec, and J. Durrant, "Recombination dynamics as a key determinant of open circuit voltage in organic bulk heterojunction solar cells: A comparison of four different donor polymers," Advanced Materials, vol. 22, no. 44, pp. 4987-4992, 2010.

[66] J. Blakesley and N. Greenham, "Charge transfer at polymer-electrode interfaces: The effect of energetic disorder and thermal injection on band bending and open-circuit voltage," Journal of Applied Physics, vol. 106, no. 3, p. 034507 , 2009.

[67] W. Wang, Z. Wang, J. Tang, S. Yang, H.Jin, G. Zhao, and Q. Li, "Seebeck coefficient and thermal conductivity in doped c60," Journal of Renewable and Sustainable Energy, vol. 1, no. 2, p. 023104, 2009. 
[68] B. Zhang, J. Sun, H. E. Katz, F. Fang, and R. L. Opila, "Promising Thermoelectric Properties of Commercial PEDOT:PSS Materials and Their Bi2Te3 Powder Composites," ACS Applied Materials and Interfaces, vol. 2, no. 11, pp. 3170-3178, 2010.

[69] O. Bubnova, Z. U. Khan, A. Malti, S. Braun, M. Fahlman, M. Berggren, and $\mathrm{X}$. Crispin, "Optimization of the thermoelectric figure of merit in the conducting polymer poly(3,4-ethylenedioxythiophene)," Nature Materials, vol. 10, pp. 429-433, 2011.

[70] C. Hu, M. Kiene, and P. Ho, "Thermal conductivity and interfacial thermal resistance of polymeric low k films," Applied Physics Letters, vol. 79, no. 25, pp. 4121-4123, 2001.

[71] S. Shenogin, A. Bodapati, P. Keblinski, and A. J. H. McGaughey, "Predicting the thermal conductivity of inorganic and polymeric glasses: The role of anharmonicity," Journal of Applied Physics, vol. 105, no. 3, p. 034906, 2009.

[72] M. Losego, L. Moh, K. Arpin, D. Cahill, and P. Braun, "Interfacial thermal conductance in spun-cast polymer films and polymer brushes," Applied Physics Letters, vol. 97, no. 1, p. 011908, 2010.

[73] M. Losego, L.Moh, K. Arpin, D. Cahill, and P. Braun, "Interfacial thermal conductance in spun-cast polymer films and polymer brushes," Applied Physics Letters, vol. 97, no. 1, p. 011908, 2010.

[74] S. Rausch, D. Rauh, C. Deibel, S. Vidi, and H. Ebert, "Thin-film thermalconductivity measurement on semi-conducting polymer material using the 3 
technique," International Journal of Thermophysics, vol. 34, no. 5, pp. 820-830, 2013.

[75] A. Henry and G. Chen, "Anomalous heat conduction in polyethylene chains: Theory and molecular dynamics simulations," Phys. Rev. B, vol. 79, p. 144305, 2009.

[76] A. Einstein, "Elementare Betrachtungen ber die thermische Molekularbewegung in festen Krpern," Annalen der Physik, vol. 340, no. 9, pp. 679-694, 1911.

[77] D. Cahill and R. O. Pohl, "Thermal conductivity of amorphous solids above the plateau," Phys. Rev. B, vol. 35, pp. 4067-4073, 1987.

[78] D. Cahill, S. K. Watson, and R. Pohl, "Lower limit to the thermal conductivity of disordered crystals," Phys. Rev. B, vol. 46, pp. 6131-6140, 1992.

[79] H. Hoppe and N. Sariciftci, "Morphology of polymer/fullerene bulk heterojunction solar cells," J. Mater. Chem., vol. 16, pp. 45-61, 2006.

[80] G. Dennler, M. Scharber, and C. Brabec, "Polymer-fullerene bulk-heterojunction solar cells," Advanced Materials, vol. 21, no. 13, pp. 1323-1338, 2009.

[81] J. C. Duda, P. E. Hopkins, Y.Shen, and M. C. Gupta, "Thermal transport in organic semiconducting polymers," Applied Physics Letters, vol. 102, no. 25, p. 251912, 2013.

[82] J. C. Duda, P. E. Hopkins, Y. Shen, and M. C. Gupta, "Exceptionally Low Thermal Conductivities of Films of the Fullerene Derivative PCBM," Phys. Rev. Lett., vol. 110, p. 015902, 2013. 
[83] G. David, "Analysis of heat flow in layered structures for time-domain thermoreflectance," Review of Scientific Instruments, vol. 75, no. 12, pp. 5119-5122, 2004.

[84] A. Schmidt, X. Chen, and G. Chen, "Pulse accumulation, radial heat conduction, and anisotropic thermal conductivity in pump-probe transient thermoreflectance," Review of Scientific Instruments, vol. 79, no. 11, p. 114902, 2008.

[85] P. E. Hopkins, B. Kaehr, L. Phinney, T. P. Koehler, A. M. Grillet, D. Dunphy, F.Garcia, and C. Brinker, "Measuring the Thermal Conductivity of Porous, Transparent SiO2 Films With Time Domain Thermoreflectance," Journal of Heat Transfer, vol. 133, no. 6, p. 073503, 2011.

[86] P. Hopkins, J. Duda, S. Clark, C. P. Hains, T. Rotter, L. Phinney, and G. Balakrishnan, "Effect of dislocation density on thermal boundary conductance across GaSb/GaAs interfaces," Applied Physics Letters, vol. 98, no. 16, p. 161913, 2011.

[87] Y. K. Koh, M. Bae, D. G. Cahill, and E. Pop, "Heat conduction across monolayer and few-layer graphenes," Nano Letters, vol. 10, no. 11, pp. 4363-4368, 2010.

[88] A. Bullen, K. O'Hara, D. Cahill, O. Monteiro, and A. von Keudell, "Thermal conductivity of amorphous carbon thin films," Journal of Applied Physics, vol. 88, no. 11, pp. 6317-6320, 2000.

[89] J. Malen, K. Baheti, T. Tong, Y. Zhao, J. Hudgings, and A. Majumdar, "Optical measurement of thermal conductivity using fiber aligned frequency 
domain thermoreflectance," Journal of Heat Transfer, vol. 133, no. 8, p. 1601, 2011.

[90] W. Yin and M. Dadmun, "A New Model for the Morphology of P3HT/PCBM Organic Photovoltaics from Small-Angle Neutron Scattering: Rivers and Streams," ACS Nano, vol. 5, no. 6, pp. 4756-4768, 2011.

[91] B. Abeles, D. S. Beers, G. D. Cody, and J. P. Dismukes, "Thermal Conductivity of Ge-Si Alloys at High Temperatures," Phys. Rev., vol. 125, pp. 44-46, 1962.

[92] R. Cheaito, J. Duda, T. Beechem, K. Hattar, J. Ihlefeld, D. Medlin, M. Rodriguez, M. Campion, E. Piekos, and P. Hopkins, "Experimental Investigation of Size Effects on the Thermal Conductivity of Silicon-Germanium Alloy Thin Films," Phys. Rev. Lett., vol. 109, p. 195901, 2012.

[93] M. Rispens, R. Meetsma, A.and Rittberger, C. Brabec, N. Sariciftci, and J. Hummelen, "Influence of the solvent on the crystal structure of PCBM and the efficiency of MDMO-PPV:PCBM plastic solar cells," Chem. Commun., vol. 0, pp. 2116-2118, 2003. 


\section{Appendix A}

\section{Journal Publications}

- Yang Shen, Louis Scudiero and Mool C. Gupta, Temperature dependence of HOMO-LUMO levels and open circuit voltage for P3HT:PCBM organic solar cells. IEEE Journal of Photovoltaics, vol. 2, no. 4, pp. 512-518, 2012.

- Yang Shen, Kejia Li, Nabanita Majumdar, Joe C. Campbell, Mool C. Gupta, Bulk and contact resistance in P3HT:PCBM heterojunction solar cells, Sol. Energy Mater. Sol. Cells., vol. 95, no. 8, pp. 2314-2317, 2011.

- Yang Shen, Christian A. Rothenbach, Anping Liu, Barada K. Nayak, David A. Paste and Mool C. Gupta, A Comparative Study of Femtosecond and Picosecond Laser Interactions with Fused Silica, (Manuscript submitted to Appl. Opt. 2013)

- Louis Scudiero, Yang Shen and Mool C. Gupta, Effect of Light Illumination and Temperature on work function of P3HT films, n-type Si and ITO. (Manuscript accepted by Appl. Surf. Sci. 2013)

- John C. Duda, Patrick E. Hopkins, Yang Shen, and Mool C. Gupta, Thermal 
transport in organic semiconducting polymers, Appl. Phys. Lett., vol. 102, no. 25, p. 251912, 2013.

- John C. Duda, Patrick E. Hopkins, Yang Shen, and Mool C. Gupta, Exceptionally Low Thermal Conductivities of Films of the Fullerene Derivative PCBM, Phys. Rev. Lett., vol. 110, p. 015902, 2013.

- Kejia Li, Yang Shen, Nabanita Majumdar, Chong Hu, Mool C. Gupta, Joe C. Campbell, Determination of free polaron lifetime in organic bulk heterojunction solar cells by transient time analysis, J. Appl. Phys., vol. 108, p. 084511084511-5, 2010 . 


\section{Appendix B}

\section{Conference Presentations}

- Yang Shen, Mool C Gupta, Investigation of Electrical Characteristics of P3HT:PCBM Organic Solar Cells, 2012 Spring IEEE PV Conference, Austin, TX.

- Yang Shen, Kejia Li, Nabanita Majumdar, Joe C. Campbell, Mool C. Gupta, Bulk and contact resistance in P3HT:PCBM heterojunction solar cells, 2011 MRS Spring Meeting, OO 10.18, San Francisco, CA.

- Yang Shen, Louis Scudiero and Mool C. Gupta, Temperature dependence of HOMO-LUMO levels and open circuit voltage for P3HT:PCBM organic solar cells, 2011 MRS Spring Meeting, OO 8.6, San Francisco, CA.

- John C. Duda, Patrick E. Hopkins, Yang Shen, and Mool C. Gupta, Temperature and thickness dependence of thermal conductivities of organic semiconducting polymers in device configurations, 2012 MRS Fall Meeting, Symposium O, Boston, MA.

- John C. Duda, Patrick E. Hopkins, Yang Shen, and Mool C. Gupta, Exceptionally low thermal conductivities of organic semiconducting polymers, 2012 
MRS Fall Meeting, Symposium B, Boston, MA.

- Kejia Li, Yang Shen, Lijun Li, Petr Khlyabich, Ellen S. Reifler, Barry C. Thompson and Joe C. Campbell; Thermal Annealing Effect on P3HT:PCBM Free Polarons Lifetime and Charge Transport, 2011 MRS Spring Meeting, B 9.11, San Francisco, CA.

- Vaishali R. Koppolu, Mool C. Gupta, Will Bagienski, Yang Shen, Chunying Shu, Harry W. Gibson, Harry C. Dorn, Organic solar cells with a blend of two solution processable electron acceptors, C60(CN)2 and PCBM, 2009 34th IEEE Photovoltaic Specialists Conference (PVSC), Philadelphia, PA.

- Vaishali R. Koppolu, Mool C. Gupta, Will Bagienski, Yang Shen, Chunying Shu, Harry W. Gibson, Harry C. Dorn, A novel solution processable electron acceptor, C60(CN)2, for bulk heterojunction photovoltaic applications, 2008 MRS Fall Meeting, Symposium P, Boston, MA. 